\title{
Final Technical Report for Phase I Award DE-SC0003559
}

Award Recipient: Springboard Engineering

Project Title: Springboard Engineering's Smart Grid Controller for Non-Smart Household Electricity-

Consuming Appliances

Project Director: Mr. Lee Glenn

Principal Investigator: Mr. Jeff Blair

The Smart Grid opens the door to the development of many companion technologies which will in turn enable the development of a variety of devices for household electricity-consuming appliances that can communicate with it; especially, many major appliance manufacturers (such as Whirlpool and General Electric) have made public commitments to design their appliances to be Smart Grid-compatible over the next several years. Yet during that same time period, customers will purchase many millions of longlasting appliances which are not compatible with the Smart Grid.

This research project's purpose is to bring significant Smart Grid compatibility to previously-installed appliances that were not specifically designed for any Smart Grid communications, in a way that is both economical and attractive for users who want to share in the energy cost savings and reduction of peak power demand opportunities provided by the evolving Smart Grid infrastructure. The focus of this effort is to identify and research smart control solutions which take advantage of the effective strategies of demand-response (DR) communications from utilities [including time-of-day (TOD) and peak-demand pricing options] and function apart from any need for operational changes to be designed into the nonsmart appliances.

Our Phase I concepts promote technological advancements for enabling devices that shift the availableuse time of millions of different appliances which otherwise have no Smart Grid capability. We researched low-cost microcontroller-based ways of creating devices with the ability to:

- maintain an accurate time and day (with no need for battery backup throughout a power outage)

- perform two-way wired and wireless communications directly with the utility company's demand management signals, to identify both low-cost time periods as well as critical-reduction periods when the cost of energy use would otherwise be much higher

- measure the power usage of the connected non-smart appliance

- remove power for a period of time from the appliance (such as a dehumidifier, portable heater, or pool pump) in response to both time-pricing schedule and critical peak-load information from the utility, or inform the user of a batch-type appliance (such as a clothes dryer or dishwasher) regarding the current cost associated with using the appliance

The new products that could be developed as a result of this research into new consumer-centric features and characteristics includes smart wall outlets, smart outlet power-monitoring adapters, smart load switches and smart remote electric rate indicators associated with the non-smart appliances.

Our Phase I goal of determining the feasibility of the above technologies was successful. The objectives were also met of developing concepts for a family of microprocessor-based control/indicator devices that can provide the above capabilities while connected in series between an appliance and its electrical power source and/or while indicating cost-of-use status to the appliance user.

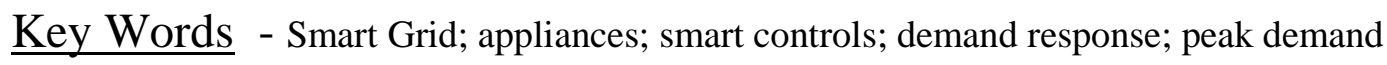




\section{Background}

In our Phase 1 proposal, "Smart Controllers for Non-smart Appliances", we presented a number of diverse technical questions centered on researching the capabilities and interface possibilities of chipsets suitable for smart device controllers for home electrical appliances, and we address these in this Phase 1 summary of our DOE-sponsored SBIR grant project activities. Specifically, the following questions were posed for Phase 1:

1) Are the newest low-cost, low-power microcontroller chipsets with open-standard wireless communication features capable of supporting the bi-directional wireless communications required by the proposed wireless Smart Grid signals from AMIs and other sources?

2) Can the wireless chipset also support the receipt of one-way time/date RF signals broadcast from the NIST signal source (based in Colorado) for accurate, battery-free timekeeping?

3) Can the chipset work together with a companion chip which supports openstandard wired AC power line broadcast signals so that both wired and wireless communication modes are supported by the same chipset?

4) Can the resulting chipset also support the smart controller function of monitoring the electric power consumed by an attached household appliance?

5) Does the chipset also have the ability to control the smart controller function of load-disable switching for household appliance loads?

6) Will the chipset also have sufficient embedded nonvolatile memory support needed to ensure secure data communication keys and embedded security features? 


\section{Task 1 - Wireless Communications}

\subsection{Phase 1 Plan}

Our Task 1 drivers were, as stated in our Phase 1 proposal's project narrative:

"Separately investigate and evaluate two microprocessor-based with integrated wireless support chipsets, the Texas Instruments CC2530 and Freescale MC13213, each as the potential basis for a secure smart controller chipset that would be adaptable enough to support the development of various smart controller devices capable of being coupled with already-installed non-smart household appliances and effectively joining them to the Smart Grid."

"This requires evaluating each chipset's native wireless communications capability between expected appliance locations (including basements) and expected AMI broadcast locations (including in-house and outside locations)."

“... we intend to investigate in Phase 1 if the chipset can detect and respond to wireless load curtailment and pricing information signals broadcast from the following sources:

- An on-premise smart meter installed by the local electric utility

- Another in-home smart appliance device"

"Both the TI CC2530 and Freescale MC13213 chipsets have an integrated 802.15.4 compliant RF transceiver which should support the main developing open communication standards being championed by many of the appliance manufacturers and other members of the wireless energy standards-making groups."

"The ability of these devices to communicate wirelessly point-to-point to each other through multiple walls/floors and over distances representative of the barriers between an outdoor electric utility meter at one end of a large home and an appliance located in the basement at the other end will be evaluated."

\subsection{Test Setup Overview}

Testing was performed in two locations: 1) in and around Springboard Engineering's headquarters in Newton, Iowa, and 2) in and around a typical private residence in Ames, Iowa.

The Springboard Engineering (SBE) site was chosen as an example of a small commercial/industrial location. About $33 \%$ of the one-story building's 40,000 square feet is open office area that includes cubicles, meeting rooms and break areas. The rest is made up of test labs, machining and molding operations. The areas are divided by wood framed, drywalled walls with a drop ceiling throughout. The outer walls are painted metal, and it has a flat, metal roof. Besides the typical EMI (electromagnetic interference) sources of a mixed-use commercial facility, the location has a Wi-Fi LAN and cell phone repeater operating. 
The private residence in Ames was chosen as an example of a typical large, ranch-style home. The structure is stick-built with a poured concrete basement. It has an " $\mathrm{H}$ "-shaped footprint with 1700 sq. ft. on both the main floor and basement levels. The siding is no-maintenance and nonmetallic, and the house has an asphalt shingled roof. The exterior walls are of typical construction for the upper Midwest, including fiber-glass insulation, particle board and barrier materials containing some metallic components. The structure was completed in 1999 and contains a typical set of appliances. There is an active Wi-Fi LAN and $2.4 \mathrm{GHz}$ cordless phone system present.

The testing required two nodes of each manufacturer's evaluation kit (Freescale's MC13213 kit and Texas Instrument's CC2530 kit), referred to within this document as the "Base" and "Remote" nodes. The two nodes sent and received a series of messages and recorded signal levels and the number of good messages received. The tests were performed with the nodes separated by varying distances, adjusted for relative antenna orientation, and with barriers of different materials placed between them. 


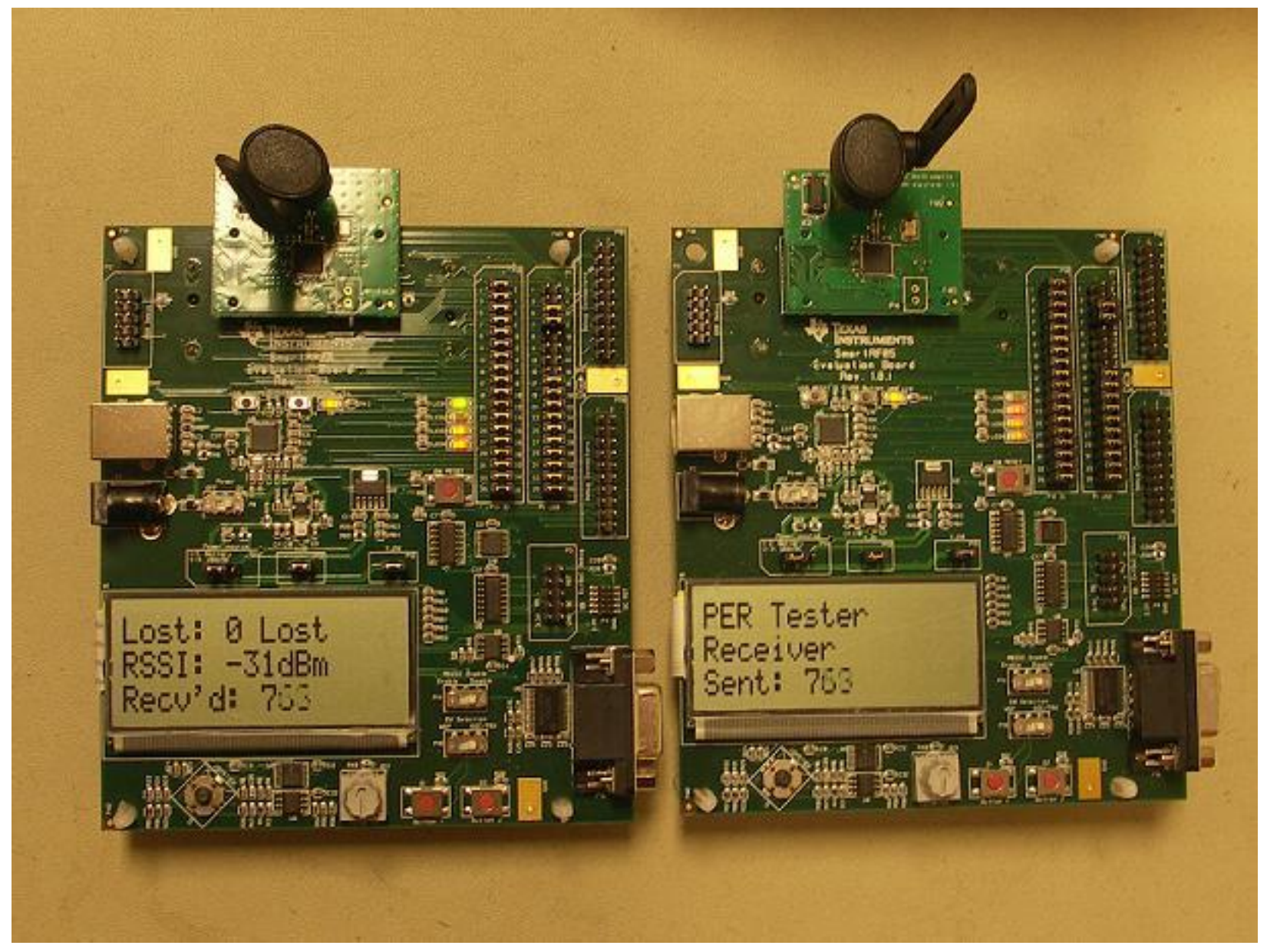

Figure 1 - Texas Instruments CC2530 Wireless Evaluation Kit

The first sets of tests were performed inside the SBE location, in a large, open, office area near the front of the building. This testing was used to determine helpful modifications to the package of software programs that came with the evaluation kits and to verify the basic functionality of the kits. It was also used to investigate signal strength related to antenna orientation. Testing proceeded at SBE with the nodes separated up to $250 \mathrm{ft}$. ( 120 m) with different and multiple structures between the node locations. This included some testing with one node outside of the building. Three test runs were performed at each node position.

The test setup at the Ames location mimicked what might be a typical confirmation of a twonode home system. Two test series were done, the first with a node placed at the service meter location on the outside of the house, and the second with a node placed at the electrical distribution panel in the basement. The other node was moved to a location within the house at or near the various major appliances. A challenging non-appliance location, where the signal was required to pass through multiple barrier types, was also included. 
All testing at both locations was done with the nodes programmed to transmit at the $1 \mathrm{~mW}$ level on $2.405 \mathrm{GHz}$. Base nodes transmitted 160 messages and waited for a reply from the Remote or a time-out before sending the next series. Messages received by the Base before the time-out and with the correct message number were counted as "good" messages and the rest counted as "bad." The major physical difference between the two manufacturer's kits was the antenna configuration. The Freescale kit uses an F-antenna integrated into the PCB trace layout, and the TI kit uses an external antenna connected to the board via coaxial connector. Both kits were running their native RF and communications stack.

\subsection{Testing Results}

Comparing the two kits, the TI kit showed higher signal strength when inside the SBE building, while the Freescale kit showed higher signal strength at the Ames location. The combination of the SBE metal structure and the more omni-directional nature of the TI antenna is the suspected reason for the stronger signals within the SBE structure, due to more reflected energy coupling with the direct signals. Even though this could indicate a performance difference between the two kits, it was found that if the signal level was above $-94 \mathrm{dBm}$, there was successful communication with both kits, and the dropped-packets-to-signal-level ratio was the same for both kits. This would indicate the signal strength as the major factor in successful communications (rather than which kit was used), and the signal strength can be affected greatly by the surrounding structure. Since this testing was not meant to be a comparative performance test of two manufacturers' kit configurations, only the data for the TI kit is shown below as representative of the effect that the structure and distances had on signal levels.

\subsubsection{Effects of the Structures}

The effect of structure can be seen in the signal level versus distance chart for the TI kit below. The dashed line represents the theoretical drop off of the signal for the test done in Ames with the Base placed at the power meter. The solid blue line is the measured data. This case is the closest of the three to a line-of-sight, no-obstruction condition. The two nodes are at roughly the same height and there are minimal conductive obstructions in the area. The green line shows what happened when the Base node was moved to the distribution panel in the basement. The SBE plot (purple line) shows significant signal coupling where the level is higher at greater distances. The overall levels are also higher than expected for the distances. 


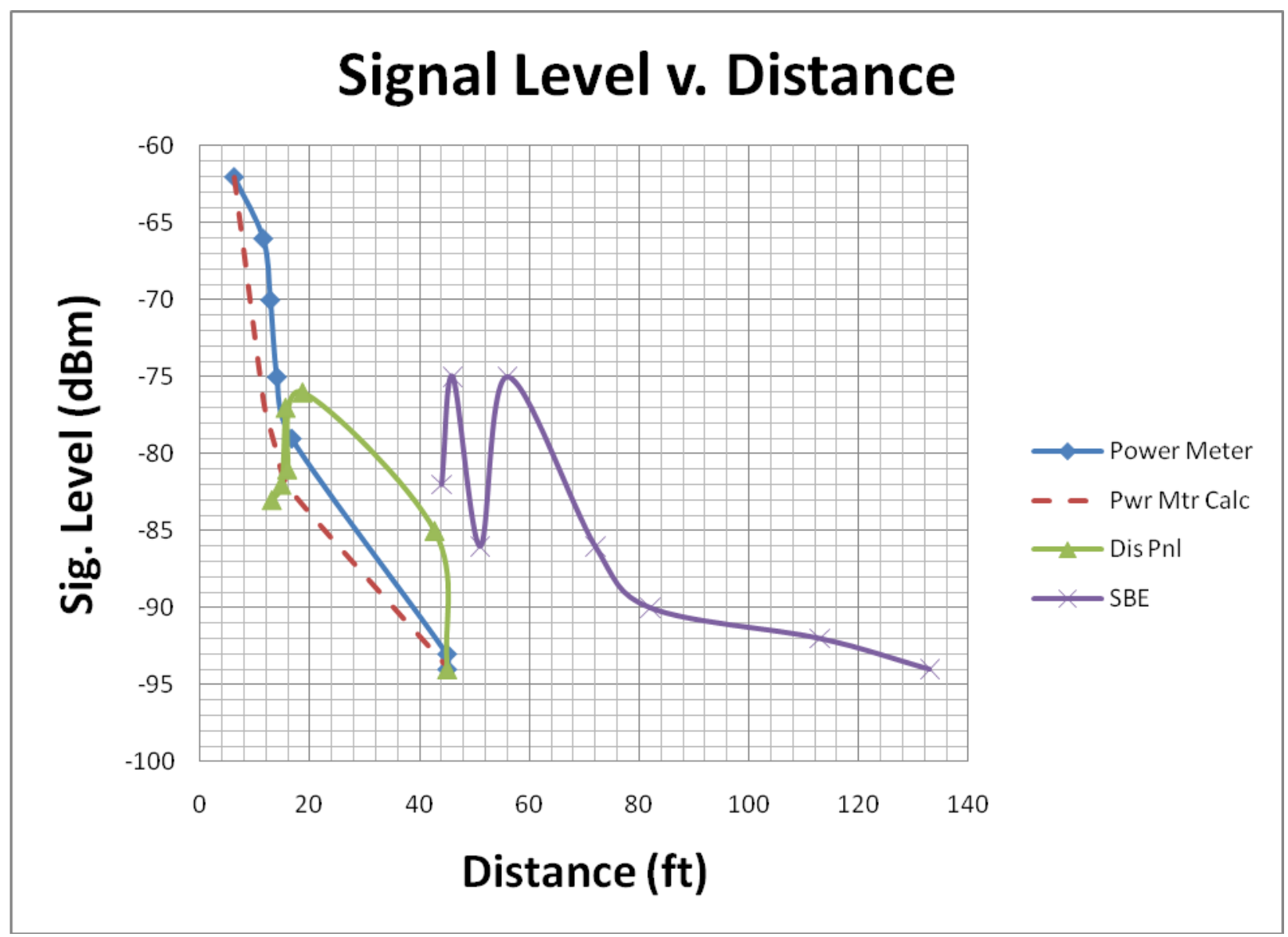

Figure 2 - Wireless Signal Levels - Theoretical and Actual

\subsubsection{SBE Site}

The table (Table 1) and diagram (Figure 3 ) below show a summary of the wireless communications test results with the TI kit at the SBE site. One node was set at Location \#1 while the other node was positioned alternately at 12 locations within or outside the building. The line-of-sight (LOS) testing was between locations marked as A and B in the diagram, where the distance and relative orientation of the antennae were varied.

\begin{tabular}{|c|c|c|c|}
\hline SBE Location & Distance $(\mathrm{ft})$ & Signal Level $(\mathrm{dBm})$ & Obstruction \\
\hline 1 & - & - & Base Location \\
\hline 2 & 46 & -75 & Single Plasterboard Walls \\
\hline 3 & 167 & No Signal & Between large metallic machines \\
\hline
\end{tabular}




\begin{tabular}{|c|c|c|c|}
\hline 4 & 113 & -92 & 3 Plasterboard Walls \\
\hline 5 & 44 & -82 & 2 Plasterboard Walls \\
\hline 6 & 82 & -90 & 4 Plasterboard Walls \\
\hline 7 & 90 & No Signal & $\begin{array}{l}2 \text { Feet outside steel building/door } \\
\text { open }\end{array}$ \\
\hline 8 & 52 & No Signal & Outside 1 foot left of window \\
\hline 9 & 61 & No Signal & $\begin{array}{l}10 \text { Feet from building, center of } \\
\text { window }\end{array}$ \\
\hline 10 & 51 & -86 & $\begin{array}{l}1 \text { Foot from building, center of } \\
\text { window }\end{array}$ \\
\hline 11 & 133 & -94 & 5 Plasterboard Walls \\
\hline 12 & 72 & -86 & Entryway, glass doors \\
\hline 13 & 56 & -75 & Entryway, inside building \\
\hline$A$ & 0 & - & Fixed \\
\hline B & 5 to 40 & -32 to -63 & None \\
\hline
\end{tabular}

Table 1 - SBE Wireless Communications Test Summary 


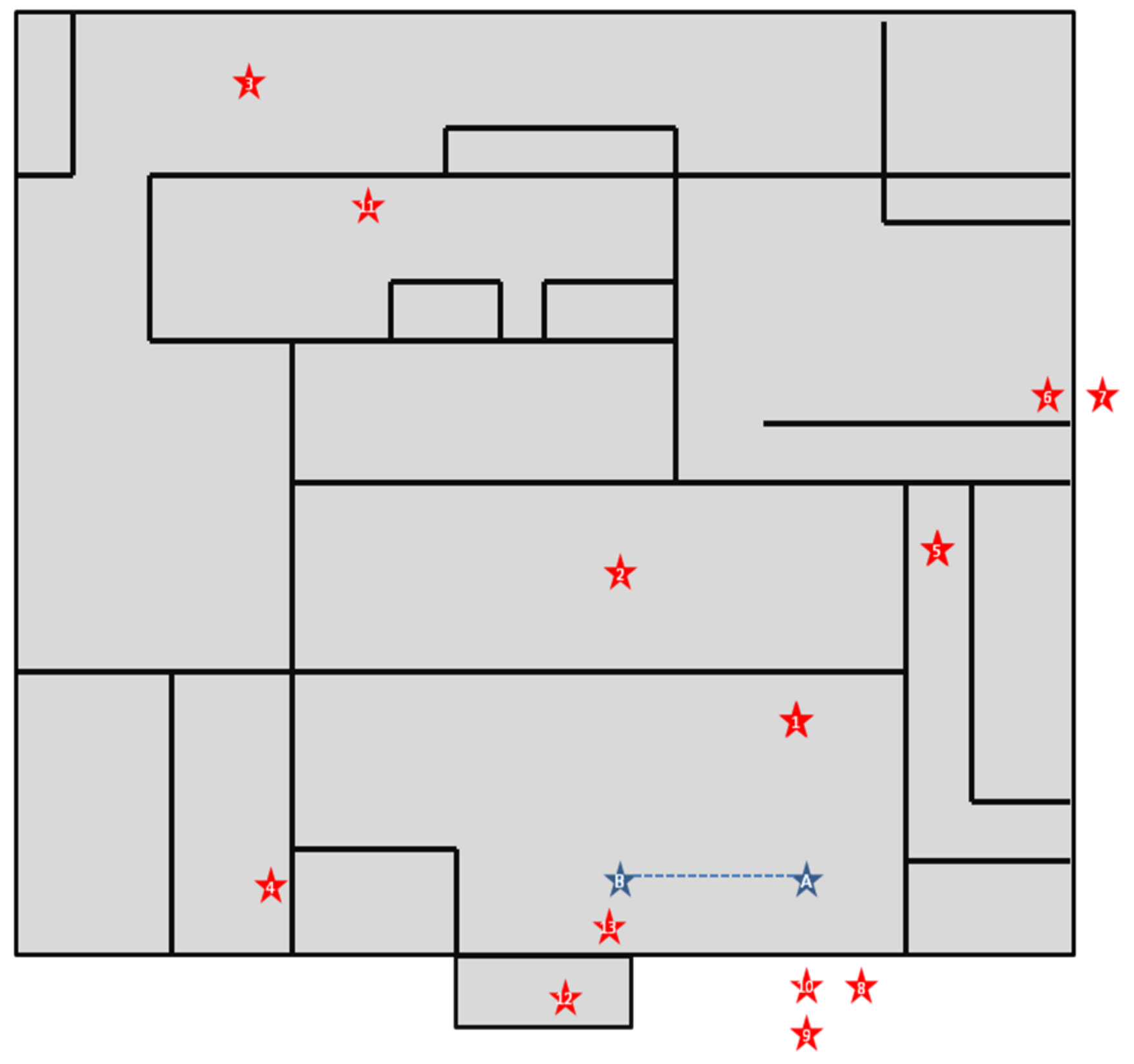

Figure 3 - SBE Building - Wireless Testing Layout

Note: All locations had test heights of 40 inches above the floor level. 


\subsubsection{Ames Site - Base at Power Meter}

The table (Table 2) and diagram (Figure 4) below show a summary of the test results of the TI kit at the Ames site. One node was set at Location \#1, the exterior-mounted electrical service meter. Locations 2 thru 6 are on the main floor of the house, and location 7 is in the basement, adjacent to the furnace control location.

\begin{tabular}{|c|c|c|c|c|c|}
\hline Location & $\begin{array}{l}\text { Lateral } \\
\text { Dis. (ft) }\end{array}$ & $\begin{array}{l}\text { Vertical } \\
\text { Dis. (ft) }\end{array}$ & $\begin{array}{l}\text { Point-to- } \\
\text { Point } \\
\text { Distance (ft) }\end{array}$ & $\begin{array}{l}\text { Signal Level } \\
\qquad(\mathrm{dBm})\end{array}$ & Obstructions \\
\hline 1 & 5.5 & 3 & 6.2 & -62 & Exterior Wall \\
\hline 2 & 14 & -2 & 14 & -75 & $\begin{array}{c}\text { Exterior Wall, Cabinet, } \\
\text { Interior Wall, Stove, } \\
\text { Dishwasher }\end{array}$ \\
\hline 3 & 16.5 & 3 & 16.7 & -79 & Exterior Wall, Interior Wall \\
\hline 4 & 12.5 & 3 & 12.8 & -70 & $\begin{array}{c}\text { Exterior Wall, Door, Interior } \\
\text { Wall }\end{array}$ \\
\hline 5 & 10.75 & 4 & 11.5 & -66 & Exterior Wall, Interior Wall \\
\hline 6 & 45 & 2 & 45 & -93 & $\begin{array}{c}3 \text { Exterior Walls, } 3 \text { Interior } \\
\text { Walls, Wood Door }\end{array}$ \\
\hline 7 & 44 & -10 & 45 & -94 & $\begin{array}{c}\text { Exterior Wall, Interior Floor, } \\
\text { Ducting }\end{array}$ \\
\hline
\end{tabular}




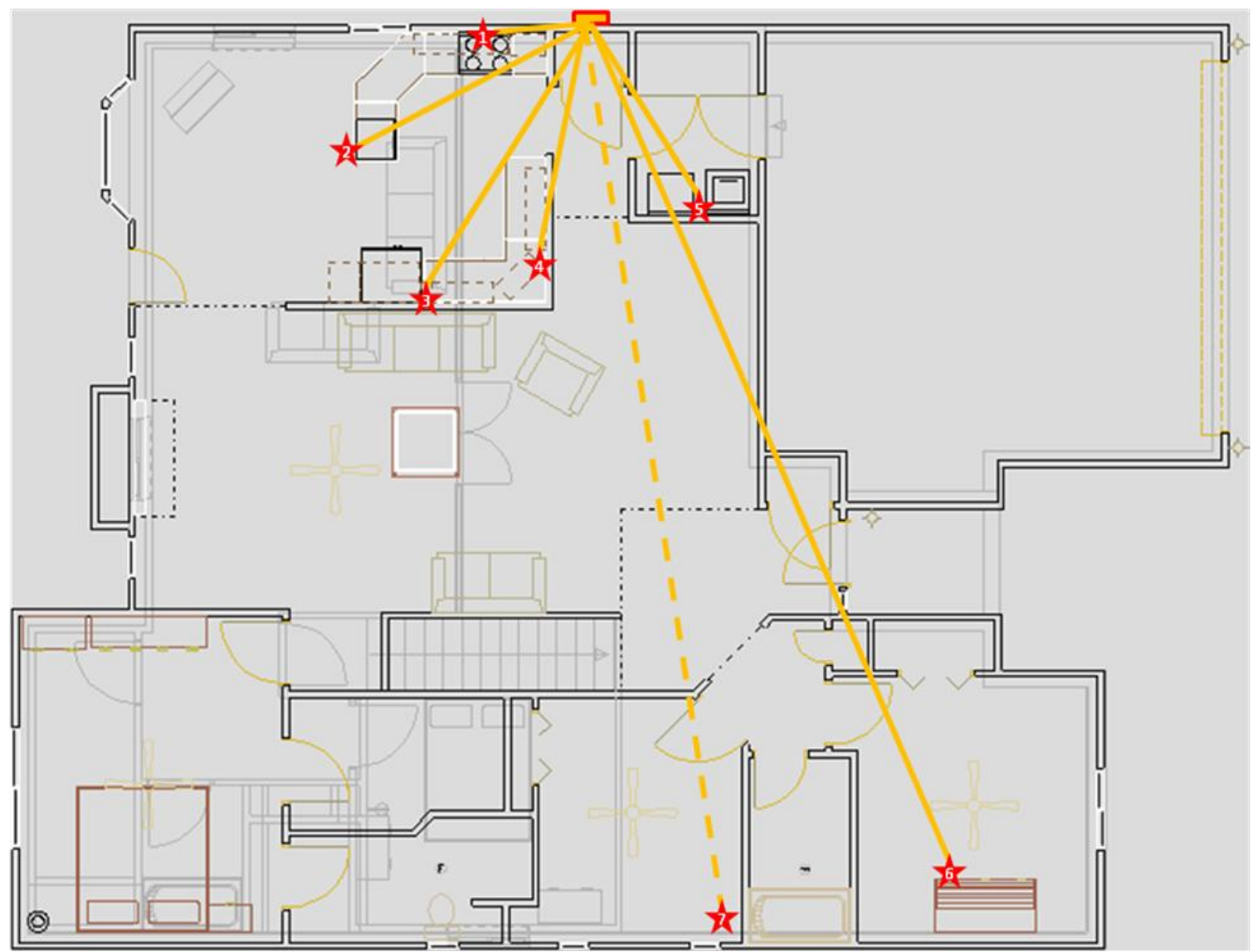

Figure 4 - Ames Residence Wireless Testing Layout (Base at Power Meter) 


\subsubsection{Ames Site - Base at Distribution Panel}

The second setup (Table 3 and Figure 5) was the same as the previous, except Location \#1 is at the power distribution panel mounted on the interior wall of the basement foundation, approximately 6 foot below grade.

\begin{tabular}{|c|c|c|c|c|c|}
\hline Location & $\begin{array}{c}\text { Lateral } \\
\text { Dis. (ft) }\end{array}$ & $\begin{array}{c}\text { Vertical } \\
\text { Dis. (ft) }\end{array}$ & $\begin{array}{c}\text { Point-to- } \\
\text { Point } \\
\text { Distance } \\
(\mathrm{ft})\end{array}$ & $\begin{array}{c}\text { Signal Level } \\
(\mathrm{dBm})\end{array}$ & Obstructions \\
\hline 1 & 5 & 12 & 13 & -83 & Floor, Cabinet, Stove \\
\hline 2 & 13 & 7 & 14.75 & -82 & Floor, Interior Wall \\
\hline 3 & 15 & 11 & 18.6 & -76 & Floor, Interior Wall, Cabinet \\
\hline 4 & 11 & 11 & 15.5 & -77 & Floor, Cabinet \\
\hline 5 & 9 & 13 & 15.8 & -81 & Floor, Washer \\
\hline 6 & 44 & 10 & 45 & -94 & $\begin{array}{c}\text { Foundation, Floor, Interior Wall } \\
\text { None, but surrounded by } \\
\text { furnace ducting }\end{array}$ \\
\hline 7 & 42.5 & -4 & 42.7 & -85 & \\
\hline
\end{tabular}

Table 3 - Ames Wireless Communications Test Summary (Base at Distribution Panel) 


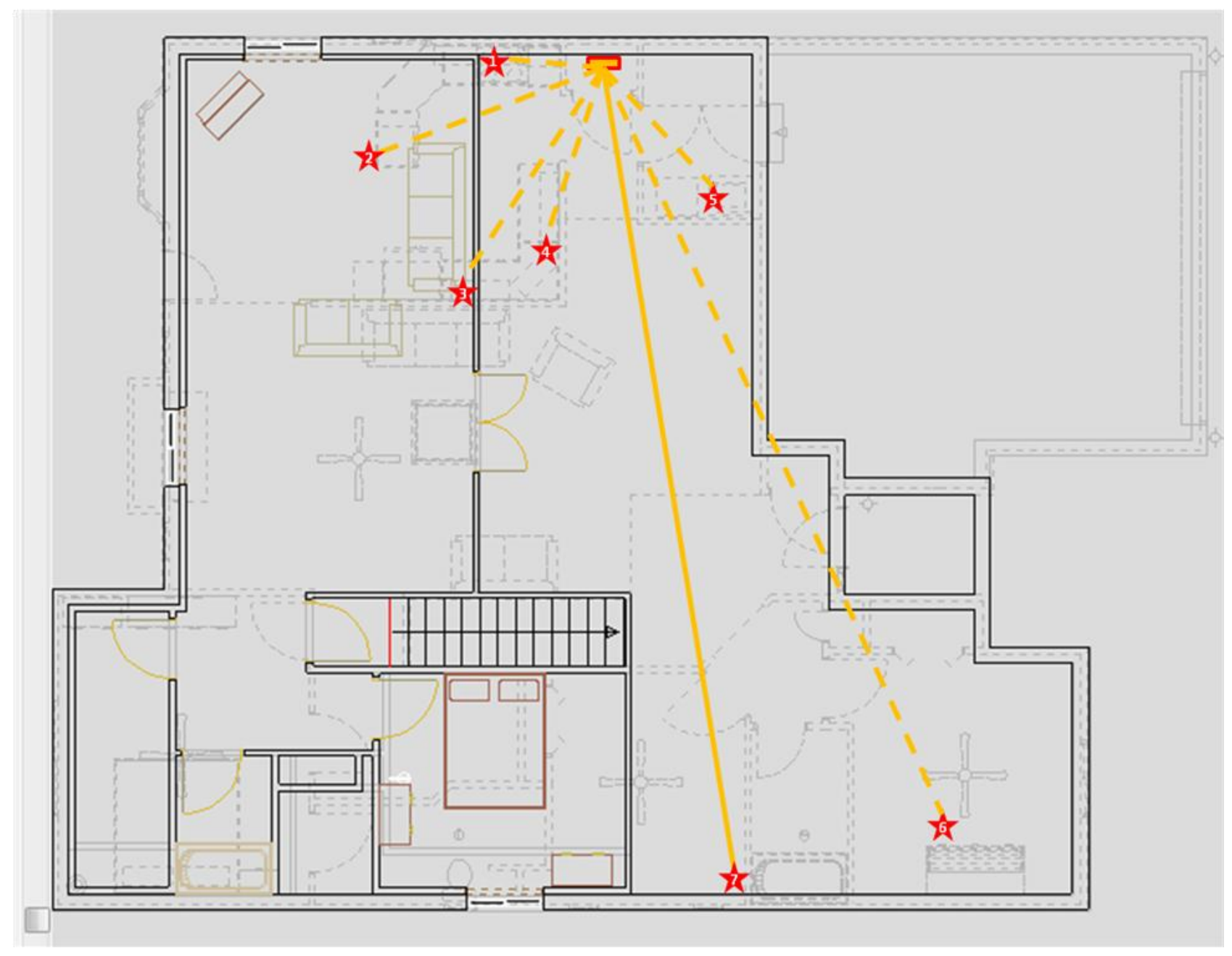

Figure 5 - Ames Residence Wireless Testing Layout (Base at Distribution Panel)

\subsection{Conclusions}

Testing at both the Springboard and Ames locations indicates that intervening structures and distance will affect the signal, and a practical/reliable communications system will likely require a centrally-located base unit, a multi-node repeater or mesh system, or a combination of both.

Both kits demonstrated similar performance, in that, if the signal level was strong enough, data would be successfully transmitted back and forth. If the signal level at the receiving node was above approximately $-94 \mathrm{dBm}(\sim 0.4 \mu \mathrm{W})$, the number of lost messages generally stayed below $10 \%$ for both kits. Signal levels below $-94 \mathrm{dBm}$ resulted in massive amounts of lost messages or no communications. Keeping the effects we have seen in this testing in mind when setting up future experiments, both development kits could be used as a basis of the platform for the rest of work under study. 
The low-powered 2.4 Ghz RF radios and antennas we investigated as part of the Freescale and Texas Instruments evaluation systems did not seem to have sufficient range for reliable communications in a point-to-point configuration (electrical meter to appliance) for a typical suburban home. We have concluded that very often, too many walls or metal barriers (such as the appliance itself) will degrade the broadcast signal to the point of being left with unsuccessful wireless communications.

In Phase 2 we plan to explore other areas for improvements, including power amplifier (PA) and/or low-noise amplifier (LNA) circuits, other standard RF frequency chipsets such as those in the $900 \mathrm{Mhz}$ band, and multi-node options. 


\section{Task 2 - Time and Date Handling}

\subsection{Phase 1 Plan}

Our Task 2 drivers were, as stated in our Phase 1 proposal's project narrative:

“... an accurate time and day-of-week must be available to the smart grid controller; in fact, to avoid customer billing surprises, the grid-connected appliance controller should know the time and day-of-week accurately regardless of the frequency and duration of power interruptions it experiences..."

"We propose to investigate a solution that involves receiving always-current time and date information from the currently-broadcast NIST signal (or other radio frequency $[R F]$ time source) ... to need no user input for setting the current time/day needed to support time-of-day usage shifting - even if the customer's communication network (or lack thereof) otherwise provides none."

"It also avoids less-favorable methods of keeping accurate time/date through power outages, such as battery-backed real-time clocks, involving issues of battery-related hazards, battery disposal and battery replacement servicing."

"[In Task 2 we will] evaluate two different methods of maintaining accurate time-of-day independent of any other in-home device, first by coupling the first chipset to a second radio chip and antenna to test the reception of the NIST's time-of-day RF broadcast signals from Colorado, and secondly by using a Cymbet EnerChip [to power a timekeeping source through powerdowns]. The first chipset's real-time clock would maintain time while the power is active and the NIST signal would be used to re-establish the proper time on each powerup [or if the NIST signal is not immediately available, time as maintained by the Enerchip]."

"We will determine if maintaining only the Greenwich Mean Time (GMT) time standard is sufficient. As an alternative method of time management, we propose to determine if the smart controller can learn the local time zone and daylight savings status (in case the utility's timebased pricing information requires this) without adding a traditional user interface requiring buttons and a display."

\subsection{Overview}

With the installation of new Smart Meters across the country (promoted in part by the DOE and the funding provided by the American Recovery and Reinvestment Act of 2009 [ARRA]), electric utility companies and energy service providers in various places are turning their attention to the creation of new customer programs that involve time-of-use incentives as part of their Demand Response plans for residential customers. In many cases, this will require the home appliance user's smart energy devices to accurately know the time and date at all times. We foresaw the advantage of such devices having ready access to the Coordinated Universal 
Time (UTC) signal continually broadcast by the National Institute of Standards and Technology (NIST). As stated by one of the reviewers to the Electric Power Research Institute's (EPRI's) 'Report to NIST on the Smart Grid Interoperability Standards Roadmap':

"What are we to do with Daylight Savings Timeshifts and timezone differences? I can only suggest that all devices subscribe to a NIST approved timebase, and communicate UTC based formats ..."

While some of the most-connected homes may have multiple sources for a "standard" time signal, including their Internet gateway, a global positioning system (GPS) source, or maybe a signal from a high-end Smart Meter, many conceivable devices to help energy user's non-smart appliances interact best with their utility's Demand Response information could benefit most from having automatic wireless time and date synchronization from outside of any Smart Grid network. Benefits could include elimination of the need for a battery to keep time and date accurate throughout power downs, elimination of user time-setting interfaces, and the ability to send accurate time and date to other in-home 'smart' devices whose designers thought it 'not my job' to ensure their own independent source for this very critical piece of the peak electricity usage management equation.

\subsection{Test/Research Setup}

To test the NIST's station WWVB time signal reception, we acquired a C-MAX evaluation kit (see Figure 6) from Digi-Key Corporation in Minnesota. This low-frequency (LF) receiver module and tuned $60 \mathrm{Khz}$ loop stick antenna in this kit have also been used in some of the desktop radio controlled clocks that have been created for the consumer market - for example, the Arcron Zeit Atomic World Time Clock model TLWA201.

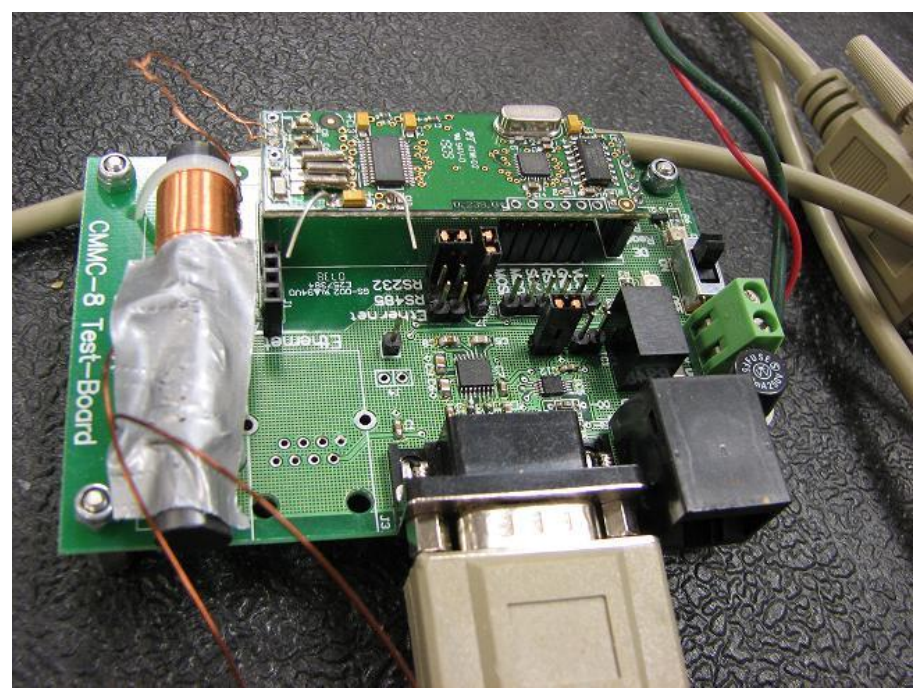

Figure 6 - C-MAX Evaluation Kit for WWVB Reception 
We also acquired a radio controlled watch made by the Japanese consumer watch innovator Casio. This watch performed exceptionally well in receiving the WWVB time signal - so well that it inspired the following question:

"How can a wristwatch with the tiniest of antennas be the best at picking up the longest wave RF signal of interest?"

Initially, we reasoned that wristwatches have the benefit of being moved around frequently on the wearer's arm, so that communication should at least be possible in some of the locations/positions the watch experiences in the period of a month (during which the watch's basic quartz accuracy should keep its time accurate to within 15 seconds or so.) While this may certainly give an advantage to wearable electronic radio devices over fixed-in-place radio devices, it does not provide a sufficient explanation - for example, our WWVB-receiving watch was designed to minimize power use, so it only tries to establish communications with the Fort Collins-based signal at four 'optimal' times the night (2:00am, 3:00am, 4:00am, and 5:00am), times when typically no one would even be wearing it!

Furthermore, our Casio watch successfully synchronizes with the WWVB signal night-after-

night even while located inside a metal desk drawer inside our large, metal-skinned, single-story office building (even though its own instruction sheet recommends making sure there are "no metal objects nearby"). In contrast, while located on top of this same desk, our C-MAX evaluation kit would not synchronize at all. [We also note that the site of the Springboard Engineering office building sits in a kind of geographic 'bowl', where the southern and western horizons (towards Fort Collins, Colorado) are less than 300 yards away.]

\section{$2.4 \quad$ Testing/Research Results}

This led us to research what differences there may be between the C-MAX time receiver module we tested (used in some desktop radio controlled clocks which retail for about \$35) and the smaller but apparently more expensive watch module (used in our Casio MTG-900DA "Wave Ceptor" watch, which retails for about $\$ 125$.

Our research turned up the fact that one of Japan's storied electronic conglomerates, OKI, partnered with Casio throughout the last decade in applying their newest semiconductor fabrication techniques to the challenges of low power and small size required by Casio's fullyfeatured solar- recharging and WWVB-receiving "Wave Ceptor" wristwatch models, which were first introduced in 2002.

According to OKI, starting with their initial ML6126 chip, OKI continued to improve their product line by integrating more and more of their watches' necessary hardware circuits onto a single large-scale integration (LSI) chip. Adding the radio receiving function to the low-power recharge function, they created the ML6190 chip. Then, finally integrating the real-time clock 
(RTC) circuitry with the rest, they created the ML6191 chip, advertised as "a first in the industry single chip LSI for radio controlled clocks" in 2004.

Their ML6191 low-power, high-performance time receiver chip, was fabricated with a novel fully-depleted Silicon-on-Insulator (SOI) process, which in 2007 was reported to be "only performed by OKI" and "mainly for radio-controlled solar watches". Prior to that, many highperformance chips for other markets were made using a partially-depleted SOI process, including high-end microprocessors such as IBM's PowerPC and Advanced Micro Device's Athlon.

According to OKI's website, the ML6191 has been discontinued - perhaps after OKI Semiconductor was acquired by ROHM Semiconductor in 2008. Our conclusion is that OKI had a superior and specialized, if more costly, technology for improving the $60 \mathrm{Khz}$ NIST reception.

In the United States, the generation and transmission strength of the time signal from the NIST site in Fort Collins, Colorado, has been continually upgraded since it was first transmitted from that location on December 1 of 1966.

Of particular interest in the scope of our research into reception of the NIST's WWVB time/date signal was the discovery that it was also included within the scope of two other recent federal solicitations - one by the US Department of Commerce's SBIR program and the other by the US Department of Defense's SBIR program. In the case of the Department of Commerce, the topic looks at the potential of changes in the WWVB modulation scheme to improve the signal robustness/quality, and while some may foresee the future of all long-distance wireless signals (including time/date signals) moving to GPS receivers, in the case of the Department of Defense, the Air Force is looking for small businesses to investigate the benefits of adding WWVB time reception to the Air Force's current GPS mobile user equipment, because as quoted from DOD SBIR 09.3, AF093-152, the GPS signal "may not always be available due to interference; therefore means of acquiring alternative timing solutions provide great benefit to the USAF. RF timing signals such as the WWV low-frequency radio stations broadcast by the National Institute of Standards and Technology (NIST) provide relatively accurate timing signals on high-power signals spectrally separated (in the RF spectrum) from GPS."

Taken together, these facts reinforce the conclusion that the promotion of an ever-improving, nationwide, low-frequency RF time source signal remains an active pursuit of the NIST's Time and Frequency Division for a multitude of public and private applications. NIST's record has been good - when discussing plans to increase the WWVB signal strength almost 14 years ago, Don Sullivan, then chief of NIST's Time and Frequency Division, presciently stated that "this will make it possible to build automatic, WWVB-controlled clocks into all kinds of appliances, even wristwatches." 


\subsubsection{WWVB Time Reception Testing Results}

After pins were soldered on the C-MAX RF receiver board so it could be connected to the evaluation motherboard, and a 5VDC switching power supply was attached to the terminal block, the demo application on the PC seemed to communicate well enough via the RS-232 interface with the C-MAX evaluation kit, but the WWVB reception seemed non-existent from the desktop near the back corner of the front room in our Springboard office building. The demo application is designed to show red, yellow or green vertical bars during reception to indicate the success of the synchronization attempt, and the results were all or nearly all red. Raising the CMAX kit up about 3' to the top of the credenza and toward the outside wall about 3' yielded just a little bit of yellow during reception tests, but nothing close to successful synchronization with the WWVB time signal broadcast from Fort Collins.

Next we moved the C-MAX kit to another computer setup near the front window which faces south. More yellow bars were seen but little green - still no success.

Later, this same configuration was taken to a country home and tried on the sill of a south-facing window in the late evening. This testing resulted in much more yellow and green, but still no successful synchronization. Some further online investigation indicated that the negative voltage generation on the C-MAX's RS-232 converter may produce enough on-board noise to overwhelm the $60 \mathrm{Khz}$ RF signal that the receiver is trying to detect. After replacing the external AC-DC converter with a 9VDC battery to help reduce power supply noise, this seemed to improve the reception somewhat. Then, after disconnecting the RS232 serial cable with the CMAX board still set to repeatedly attempt synchronization and then re-connecting the cable after several minutes, the radio clock reported to the PC application a successful "Last Synchronization" time stamp for the first time. Left running overnight, the last "successful" sync was reported near sunup, although the year was reported erroneously as ' 90 ' rather than ' 10 '.

A few nights later, the older 9VDC battery was exchanged for a fresh one, and several inches of wire in a twisted pair were added to the battery connector. With this configuration, successful synchronization could be achieved at the country home in either of two ways: 1) by removing the serial cable, or 2) by physically holding onto the $9 \mathrm{~V}$ battery (which has a standard painted metal case, electrically isolated from either terminal.) This latter result was very repeatable and remarkable, but also very difficult to explain: whether the human body was acting as an additional antenna or as a frequency-shifting capacitance to improve the signal or as a shunt path for system noise, it was hard to guess. Left overnight with the serial cable still attached and talking with the C-MAX evaluation program on the laptop, and with the battery wrapped in a foil wrapper and wedged next to the laptop body, it was found that the C-MAX evaluation kit would also sync.

In Figure 7 below are the results observed on Saturday morning, March 6, 2010, at 8:21 AM local time (UTC-6). 

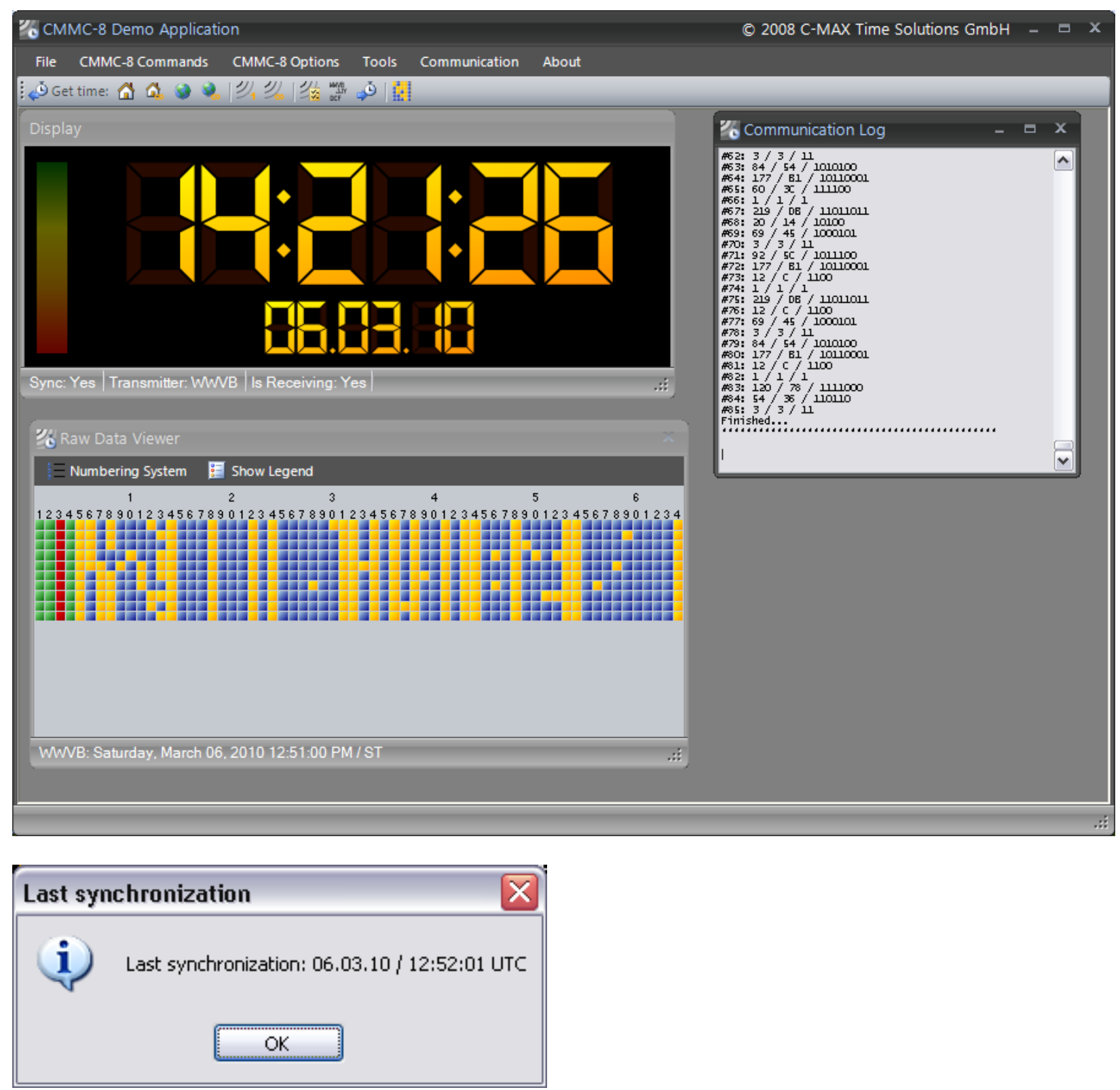

Figure 7 - Early Morning Synchronization Results

The last sync time dates to about an hour-and-a-half earlier, or near sunup locally. It also shows evidence of one or more bit errors in most of the ten "good" synchronization attempts that occurred in the preceding 20 minutes (since 12:31 UTC) - so successful reception was getting 'iffy' at that point, if not earlier. This helps explain why our Casio watch always shows its last successful synchronization at 3 minutes past the hour - three consecutive reception strings, each 
taking 1 minute to arrive at $60 \mathrm{Khz}$, are required to match bit-for-bit in the unchanging bit fields to help verify the integrity of the received WWVB time signal data.

Additional testing at Springboard with this configuration (except with a desktop PC replacing the laptop) in the south-facing window and also in the glassed-in entry way of the Springboard facility (where AT\&T cell phone reception was reported to have improved previously) did not show any green bars, just more yellow bars, and synchronization was never achieved. Here, there also did not appear to be any improvement gained by holding the battery or touching the antenna. [See Figure 8 below.]

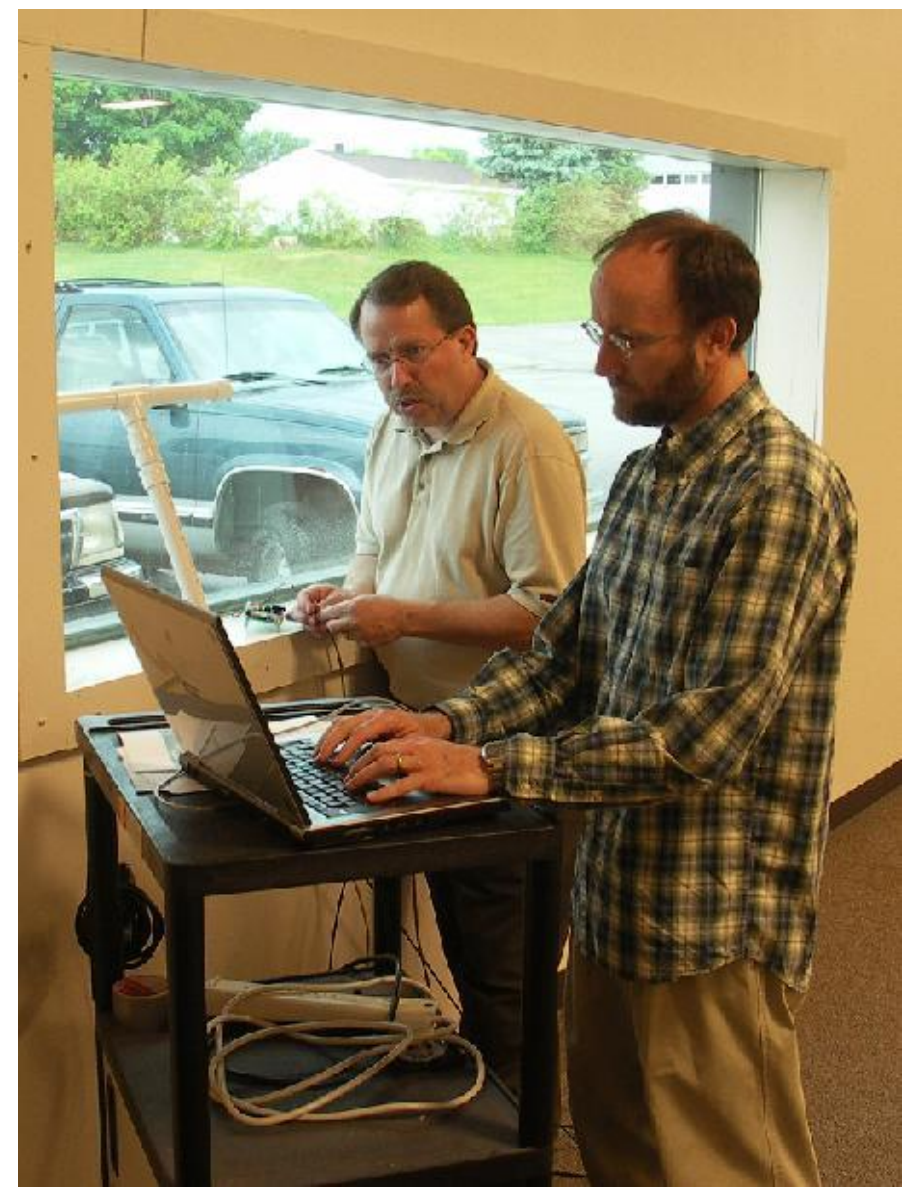

Figure 8 - C-MAX Time Reception Setup at Springboard

We note that this initial testing at Springboard Engineering was done during the daylight hours only, and that the Springboard facility is in somewhat of a geographic bowl, with a land rim as high as the single-story commercial building beginning a few hundred yards away on both the South and West sides - toward Fort Collins, Colorado.

It seems clear from both our testing and the research we have done, that the state of WWVB reception with the typical radio controlled desk clock hardware is: 
a) far better at receiving successfully in the nighttime hours than in the daytime hours,

b) unlikely to work well or at all in certain geographic locations,

c) much more likely to synchronize in the most-optimal interior positions than in the least-optimal positions, and

d) suffering from poor signal-to-noise ratio due to both poor signal pickup strength and high relative noise floor.

For improvements to the signal level, exploring improved antenna designs seems especially promising. Several options exist, including designs using Litz wire, open loop designs, and/or an antenna system that could be installed somewhat remotely from the WWVB receiver. We would like to create and verify a much-improved antenna design in Phase 2 of this project.

On the noise side, it seems particularly important to shield the $60 \mathrm{KHz}$ receiver from other power supply and other system noise sources, so the design of the receiver module seems critical.

As demonstrated with our watch, addressing these two areas should allow the concept of WWVB reception for always-accurate time and date to work in the majority of currently unsuccessful, but desirable geographic locations and interior positions.

\subsubsection{Battery Backup Investigation}

We also wanted to investigate the Cymbet EnerChip as a possible eco-friendly means of maintaining power to run a smart device's timekeeping circuitry in case a new time sync cannot be immediately achieved upon each powerup. The EnerChip differs from traditional batteries in that it contains no hazardous or flammable materials, can be reflow soldered, and is designed to last the life of devices it powers.

To evaluate this we acquired Cymbet's CBC-EVAL-05 kit which included two different EnerChip devices, the CBC3112 (12uAh capacity) and the CBC3150 (50uAh capacity). These rechargeable, solid state energy sources with integrated power management circuitry were analyzed for potential use in keeping a real-time clock chip actively maintaining time and day throughout a power outage.

\subsubsection{EnerChip Testing Results}

A test circuit was connected to experiment with the CBC3112. All basic functionality of the chip performed as intended. The reset output signal went low when VDD was removed. The internal protection circuit shut off the output when the battery voltage dipped below approximately $3 \mathrm{vdc}$.

Further experimentation was conducted to measure the rated output power capability. A 150 Kohm resistor was placed in series with a $1 \mathrm{Kohm}$ resistor on the output pin to ground. With this arrangement, a $25 \mathrm{uA}$ current drain was expected. The $1 \mathrm{Kohm}$ resistor was connected to an 
oscilloscope to measure the load current ( $1 \mathrm{mv}$ measured output equals $1 \mathrm{uA}$ current). When the charging power supply was removed from VDD, the output voltage settled in to $3.75 \mathrm{vdc}$, and the current measured was indeed $25 \mathrm{uA}$. The expectation was that the chip should supply this current for approximately $1 / 2$ hour ( $12 \mathrm{uAh}$ rated capacity); however, the battery voltage dropped to below $3 \mathrm{vdc}$ after only 10 minutes and activated the internal battery protection cut-off. This equates to only $30 \%$ of the expected capacity. Reflection upon this experiment brought the consideration that perhaps the battery was being over-loaded with $25 \mathrm{uA}$ current draw. Review of the literature provided with the evaluation kit did not indicate a maximum rated output current. Contact was made with an engineering representative at Cymbet, who confirmed that too much output current may drive the battery to the $3 \mathrm{vdc}$ threshold and into cut-off. He indicated that there isn't a designed max output current; however, the rated output current is 8 $\mathrm{uA}$. The test circuit was then revised by replacing the $150 \mathrm{Kohm}$ resistor with a $330 \mathrm{Kohm}$ resistor. The expected and subsequently measured output current was approximately $8 \mathrm{uA}$; however, the battery voltage dropped to the $3 \mathrm{~V}$ cutoff after about 1 minute. The conclusion was that the $12 \mathrm{uAh}$ battery circuit may have been damaged by the previous, higher load current. This discovery is critical input for future designs with this chip.

Testing then switched to the 50 uAh capacity CBC3150 chip using a 470 Kohm resistor and the 1 Kohm measurement resistor in series for a load. The circuit operated at approximately $8.5 \mathrm{uA}$ for over 5 hours and finally went into cut-off after 5 hours and 45 minutes. The approximate output was calculated to be $46.75 \mathrm{uAh}$, indicating that the device delivers very closely to the data sheet expectation of $50 \mathrm{uAh}$ maximum.

Real-time clock (RTC) or counter chips are readily available that have adequate resolution, low power use (ranging from $130 \mathrm{nA}$ to $10 \mathrm{uA}$ in standby current), and the ability to interface with a microprocessor, making them suitable options for backup timekeeping during power outages. The Texas Instruments bq4802LY was analyzed as one potential RTC that might use the EnerChip as a backup power source. This RTC requires less than $500 \mathrm{nA}$ of operating current in backup mode use; therefore the $50 \mathrm{uAh}$ chip from Cymbet should be able to operate it for power outages up to 100 hours in duration (over 4 days), which should be sufficient for most applications.

\subsection{Conclusions}

\subsubsection{WWVB Signal Reception Conclusions}

Our Phase 1 research shows that the low-frequency (LF) band, $60 \mathrm{Khz}$ WWVB time/date synchronization signal from the NIST transmitter site near Fort Collins, Colorado, is very difficult to detect reliably with a standard consumer desktop radio controlled clock unit fixed in a typical appliance location inside a home, yet we have demonstrated good results with our premium watch sample. We believe that to improve receptivity, additional research and development is warranted, particularly in the areas of WWVB antenna system design and receiver module layout. 
[Note: As recommended by NIST special publication 960-14 (2009 version), we have used the phrase "radio controlled clock" rather than "atomic clock", as the latter is not technically correct for products that do not contain an atomic oscillator, such as a cesium or rubidium oscillator. A radio-controlled clock, then, is one with a radio inside that receives the time signal from an atomic clock source. In contrast, per the NIST's website, their Atomic Devices and Instrumentation Group has actually created chip-mounted structures about the size of a grain of rice that do embody atomic-level timing means and could rightly be called atomic clock chips.]

\subsubsection{EnerChip Backup Power Source Conclusions}

Our conclusion here is that a solid state micro-energy battery such as the Cymbet devices we tested should be easily capable of providing backup power to an RTC. At under $\$ 1$ per unit at modest volumes, they could be connected in parallel to achieve even longer backup times, if needed.

Depending upon the application, a super capacitor could also work for an RTC application. Their main disadvantages compared to the Cymbet devices appear to be the internal discharge rate of a super capacitor and their larger physical size. 


\section{Task 3 - Wired Communications}

\subsection{Phase 1 Plan}

Our Task 3 drivers were, as stated in our Phase 1 proposal's project narrative:

".... we intend to investigate in Phase 1 if the same chipset can detect and respond to wired load curtailment or pricing information signals from a source broadcasting on the in-home AC power line."

"Can the chipset work together with a companion chip which supports open-standard wired AC power line broadcast signals so that both wired and wireless communication modes are supported by the same chipset?"

"Since some of the home network groups are promoting a power line carrier broadcast signal solution to in-home energy networks, it would be important for a universal chipset to support this means of communication in addition to wireless. We propose to determine the feasibility of using the same chipset above to support this functionality of a smart controller for non-smart appliances."

\subsection{Test Setup Overview}

Power Line Communications (PLC) uses the existing electrical wiring in a structure as the pathways of communications by impressing a high frequency carrier with digital data on top of the AC voltage, in effect, making the electrical outlets in that structure also function as data ports. For testing this method, a three-module Yitran IT700 Starter Kit was purchased from distributor Future Electronics (Figure 9 below). One module was configured as the Base (or Network Coordinator), and the remaining two modules were configured as Remote Stations to form a basic 3-node network. 


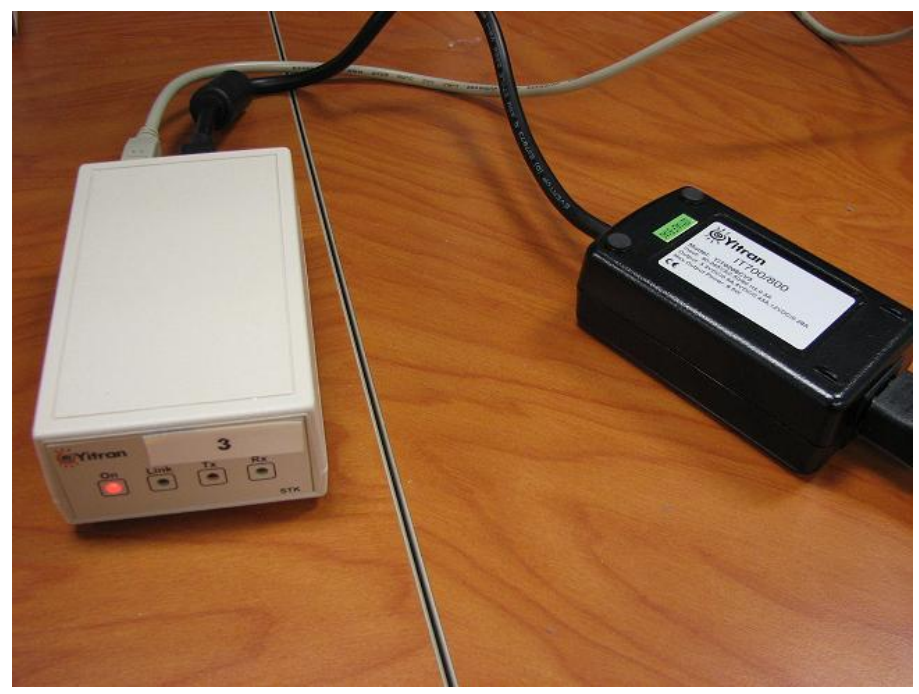

Figure 9 - Yitran PLC Module

Testing was performed at three locations: 1) at the Springboard Engineering [SBE] office building, 2) at a ranch style house in Ames, Iowa [Ames], and 3) at a two-story, colonial-style house in Urbandale, Iowa [Urbandale]. The circuit panels at SBE were installed in 2007 and are fed from the facility's master distribution panel via a $75 \mathrm{KVA}, 480$ to 120/206 VAC transformer. The other two locations are typical split 240 VAC residential installations. Ames has a 200-Amp service, installed in 1999, and Urbandale has a 100-Amp service dating from 1967.

Due to ordering difficulties, the PLC evaluation kit arrived late in the schedule period, and it did not include the tools needed to modify the nodes' embedded software. This limited the possible test configurations and any reconfiguration of the data collection. The preprogrammed routine allowed for transmission of a string of data at roughly 0.5 second intervals and the reporting of received data every 5 seconds through Yitran's IT700PLC Studio software. To do simultaneous data collection and local control required a PC running the studio software for each node. This complicated the setup and running of the tests and resulted in some data loss due to the log file being overwritten in a few instances.

\subsubsection{Equipment Configuration}

At SBE the AC power line circuits are split between phases and between two panels. The PLC communication nodes were connected at SBE with the Base and one Remote connected to circuits sharing a phase and panel. The second Remote was connected to a circuit on the other phase in the second panel. At Ames the nodes were configured with the Base and one Remote node connected to one phase and the second Remote node connected to the second phase. At Urbandale, all three nodes were connected to circuits on the same phase of the panel. This was done because during the setup it was discovered the communications signal would not jump 
phases at the Urbandale location. All nodes were connected to individual PCs running the IT700PLC Studio application.

\subsubsection{Basic Test}

In the basic test, only one node at a time was broadcasting. The active node would send 10 messages to one listening node, then 10 messages to the second listening node and finally 10 messages as a network-wide cast to all nodes. Tests at SBE were done with and without surge protecting power strips. The presence of the strip did not appear to change the performance of the system. The testing at Ames and Urbandale was done with protective power strips.

\subsubsection{Round Robin Test}

In this test, all the nodes are broadcasting at the same time to one other node. The Base node would broadcast to the first Remote, the first Remote to the second Remote and the second Remote to the Base. This was only done at Ames and Urbandale.

\subsubsection{All Broadcast Test}

In this test all three nodes send out a network-wide broadcast at the same time. This was only done at Ames and Urbandale.

\subsection{Testing Results}

The IT700PLC Studio software records the following data:

- Record index

- Date and time

- Network number

- Originating node number

- The node number next in the network

- The node number the target node receives the message from

- Target node number

- $\quad$ Signal quality $(0=$ Poor, $31=$ Best $)$

- Contention Window - Number of "quiet" time intervals on net before transmission is allowed

- Data rate (Mode $\mathrm{SM}=7.5 \mathrm{kbps}, \mathrm{RM}=5 \mathrm{kbps}, \mathrm{ERM}=2.5 \mathrm{kbps}$ )

- Service Type (ACK: expect acknowledgement; UNACK: no acknowledgement)

- Transmission type (to node \#; all nodes on same network; Different network)

- Port used

- Message

The testing in this task focused on signal quality items: how many of the sent messages were received, what was the signal quality value, what was the data rate and how long was the contention window. 


\subsection{1 $\quad$ SBE Testing Results}

The testing done at the Springboard Engineering facility was to establish basic functions of the network and help define the testing to be done at the two residential sites. The table below summarizes the results.

\begin{tabular}{|c|c|c|c|c|c|c|c|c|c|c|c|c|c|}
\hline \multirow{3}{*}{$\begin{array}{l}\text { SBE } \\
\text { Sending } \\
\text { Node }\end{array}$} & & \multirow{2}{*}{\multicolumn{2}{|c|}{$\begin{array}{l}\text { Signal } \\
\text { Quality }\end{array}$}} & \multirow{2}{*}{\multicolumn{2}{|c|}{ Data Rate }} & \multirow{2}{*}{\multicolumn{2}{|c|}{$\begin{array}{c}\text { Contention } \\
\text { Window }\end{array}$}} & & & & & & \\
\hline & \multirow{2}{*}{$\begin{array}{l}\text { Receive } \\
\text { Node }\end{array}$} & & & & & & & Mgs & Mgs & \multicolumn{3}{|c|}{$\begin{array}{l}X=\text { Surge } \\
\text { Protection }\end{array}$} & \multirow[t]{2}{*}{ Notes } \\
\hline & & $\operatorname{Max}$ & Min & $\operatorname{Max}$ & Min & $\operatorname{Max}$ & Min & & & 1 & 3 & 4 & \\
\hline 4 & 3 & 30 & 30 & 7.5 & 7.5 & 10 & 10 & 10 & 10 & $x$ & $\bar{x}$ & $\bar{x}$ & \\
\hline 4 Broadcast & 3 & 30 & 30 & 5 & 5 & 80 & 36 & 10 & 10 & 0 & $\bar{x}$ & 0 & $\begin{array}{l}\text { Power on } \\
3 \text { cycled }\end{array}$ \\
\hline 4 Broadcast & 3 & 30 & 30 & 5 & 5 & 11 & 10 & 10 & 10 & $x$ & 0 & $x$ & \\
\hline 4 Broadcast & 3 & 30 & 30 & 5 & 5 & 11 & 10 & 10 & 10 & $x$ & $x$ & $x$ & \\
\hline 1 & 3 & 21 & 15 & 7.5 & 7.5 & 11 & 10 & 10 & 10 & $x$ & $x$ & $x$ & \\
\hline 1 Broadcast & 3 & 31 & 31 & 5 & 5 & 14 & 12 & 10 & 7 & 0 & 0 & 0 & \\
\hline 1 Broadcast & 3 & 31 & 31 & 5 & 5 & 12 & 11 & 10 & 10 & 0 & 0 & $x$ & \\
\hline 1 Broadcast & 3 & 31 & 31 & 5 & 5 & 80 & 11 & 10 & 10 & 0 & $x$ & $x$ & $\begin{array}{l}\text { Power on } \\
3 \text { cycled }\end{array}$ \\
\hline 1 Broadcast & 3 & 31 & 31 & 5 & 5 & 13 & 12 & 10 & 10 & $x$ & $\bar{x}$ & $x$ & \\
\hline 1 Broadcast & 3 & 31 & 31 & 5 & 5 & 11 & 11 & 10 & 9 & $x$ & $x$ & $x$ & \\
\hline 3 & 1 & 31 & 31 & 7.5 & 7.5 & 11 & 11 & 20 & 20 & $x$ & $x$ & $x$ & \\
\hline 3 Broadcast & 1 & 31 & 31 & 5 & 5 & 11 & 10 & 10 & 10 & $x$ & 0 & $x$ & \\
\hline 3 Broadcast & 1 & 31 & 31 & 5 & 5 & 80 & 13 & 10 & 10 & $x$ & $x$ & $x$ & $\begin{array}{l}\text { Power on } \\
1 \text { cycled }\end{array}$ \\
\hline 4 & 1 & 30 & 30 & 5 & 5 & 11 & 10 & 10 & 10 & $x$ & $x$ & $x$ & \\
\hline 4 Broadcast & 1 & 30 & 30 & 5 & 5 & 80 & 36 & 10 & 10 & $x$ & 0 & 0 & Initial net \\
\hline
\end{tabular}




\begin{tabular}{|c|c|c|c|c|c|c|c|c|c|c|c|c|c|}
\hline & & & & & & & & & & & & & setup \\
\hline 4 Broadcast & 1 & 31 & 31 & 5 & 5 & 12 & 11 & 10 & 10 & 0 & 0 & $x$ & \\
\hline 4 Broadcast & 1 & 30 & 30 & 5 & 5 & 11 & 10 & 10 & 10 & $\mathrm{x}$ & 0 & $x$ & \\
\hline 4 Broadcast & 1 & 30 & 30 & 5 & 5 & 11 & 10 & 10 & 10 & $x$ & $x$ & $x$ & \\
\hline 1 & 4 & 30 & 30 & 7.5 & 7.5 & 10 & 10 & 10 & 10 & $x$ & $x$ & $x$ & \\
\hline 1 Broadcast & 4 & 30 & 30 & 5 & 5 & 80 & 11 & 20 & 20 & $x$ & $x$ & $\mathrm{X}$ & $\begin{array}{l}\text { Power on } \\
4 \text { cycled }\end{array}$ \\
\hline 3 Broadcast & 4 & 30 & 30 & 5 & 5 & 12 & 11 & 10 & 10 & 0 & 0 & $x$ & \\
\hline 3 Broadcast & 4 & 30 & 30 & 5 & 5 & 80 & 13 & 10 & 10 & 0 & 0 & 0 & $\begin{array}{l}\text { Power on } \\
4 \text { cycled }\end{array}$ \\
\hline 1 Broadcast & 4 & 29 & 13 & 5 & 5 & 14 & 12 & 10 & 7 & 0 & 0 & 0 & \\
\hline 3 Broadcast & 4 & 30 & 30 & 5 & 5 & 12 & 11 & 10 & 9 & 0 & 0 & 0 & \\
\hline
\end{tabular}

Table 4 - SBE Summary

\subsubsection{SBE Results Analysis}

Signal Quality: At or near the "Best" level. Min values differed greatly from Max only once for these particular tests. Only one test showed a consistent low signal quality.

Date Rate: Data rate generally appears to be tied to the type of transmission: Node to Node was mostly $7.5 \mathrm{kbps}$ and Network Broadcasts were always at $5 \mathrm{kbps}$.

Contention Window: The window length was extremely long, as much as 80 when the node was first establishing conductivity with the network, but once established, the window size ranged from 9 to 14. The only large numbers were seen at the initialization of the network or after the node's power was cycled (causing it to re-establish its place in the network).

Surge Protection: Powering the node through a surge suppression device didn't appear to affect the functionality of the node or the network. In most cases, the Signal Quality varied by only 1 quality point. The cases where the total number of sent messages was not received occurred, except in a single case, with all nodes not using a suppression device.

\subsubsection{Residential Locations Testing Results}

The residential testing used surge protection devices on all nodes. 
There were four different test scenarios:

- One node transmitting to only a second node

- One node transmitting to all nodes

- Node 1 transmitting to Node 3, Node 3 transmitting to Node 4, Node 4 transmitting to Node 1. All at the same time.

- All three nodes transmitting to all nodes at the same time.

\subsubsection{Ames Testing Results}

Node 1 is the Network Coordinator, and nodes 3 and 4 are the Remotes. Node 1 was placed in the basement near the power panel and connected with a circuit of the same phase as Node 4 . Node 3 was connected to a circuit in the kitchen on the main floor, connected to the other phase of the power panel. Node 4 was placed in a bedroom furthest from the panel, connected to the same power phase as Node 1 .

Details are shown in Table 5 - Table 8 below.

\begin{tabular}{|c|c|c|c|c|c|c|c|c|c|c|}
\hline \multirow{3}{*}{$\begin{array}{l}\text { Ames } \\
\text { Sending } \\
\text { Node }\end{array}$} & \multirow{3}{*}{$\begin{array}{l}\text { Receive } \\
\text { Node }\end{array}$} & \multirow{3}{*}{\multicolumn{2}{|c|}{ Signal Quality }} & \multirow{3}{*}{\multicolumn{2}{|c|}{ Data Rate }} & \multirow{3}{*}{\multicolumn{2}{|c|}{$\begin{array}{l}\text { Contention } \\
\text { Window }\end{array}$}} & \multirow{4}{*}{$\begin{array}{l}\text { Mgs } \\
\text { Sent }\end{array}$} & \multirow{4}{*}{$\begin{array}{l}\text { Mgs } \\
\text { Rec }\end{array}$} & \multirow{4}{*}{ Notes } \\
\hline & & & & & & & & & & \\
\hline & & & & & & & & & & \\
\hline & & Max & Min & Max & Min & Max & Min & & & \\
\hline 1 & 3 & 31 & 31 & 7.5 & 7.5 & 11 & 10 & 25 & 25 & \\
\hline 1 & 4 & 31 & 31 & 7.5 & 7.5 & 10 & 9 & 25 & 24 & \\
\hline 3 & 1 & 31 & 31 & 7.5 & 7.5 & 80 & 17 & 25 & 25 & Initial net setup \\
\hline 3 & 4 & 31 & 31 & 7.5 & 7.5 & 15 & 13 & 25 & 25 & \\
\hline 4 & 3 & 31 & 15 & 7.5 & 7.5 & 11 & 10 & 25 & 25 & \\
\hline 4 & 1 & 31 & 31 & 7.5 & 7.5 & 10 & 10 & 25 & 24 & \\
\hline
\end{tabular}

Table 5 - Ames Signal Node to Signal Node

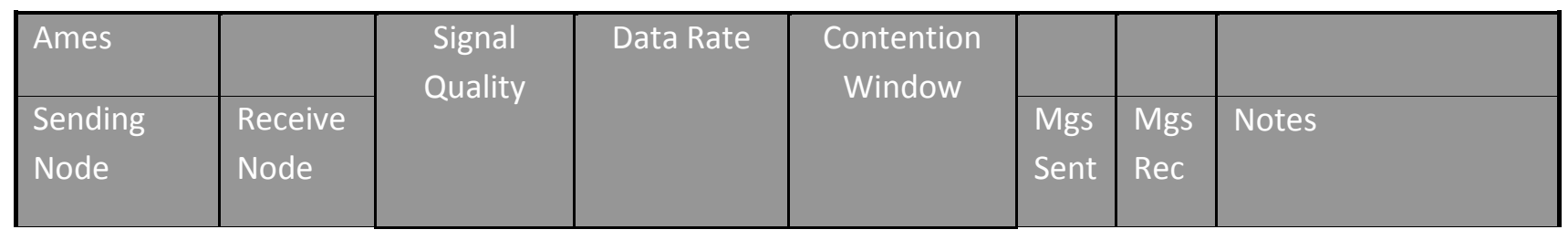




\begin{tabular}{|l|r|r|r|r|r|r|r|r|r|l|}
\hline & & Max & Min & Max & Min & Max & Min & & & \\
\hline 1 Broadcast & 3 & 31 & 31 & 5 & 5 & 11 & 9 & 25 & 48 & 27 relayed thru 4 \\
\hline 1 Broadcast & 4 & 31 & 31 & 5 & 5 & 12 & 9 & 25 & 39 & 18 relayed thru 3 \\
\hline 3 Broadcast & 1 & 31 & 31 & 5 & 5 & 13 & 11 & 25 & 24 & 1 relayed thru 4 \\
\hline 3 Broadcast & 4 & 31 & 31 & 5 & 5 & 13 & 12 & 25 & 24 & \\
\hline 4 Broadcast & 3 & 31 & 31 & 5 & 5 & 12 & 10 & 25 & 30 & 5 Relayed thru 1 \\
\hline 4 Broadcast & 1 & 31 & 31 & 5 & 5 & 12 & 10 & 25 & 33 & 13 relayed thru 3 \\
\hline
\end{tabular}

Table 6 - Ames Signal Node to All Nodes

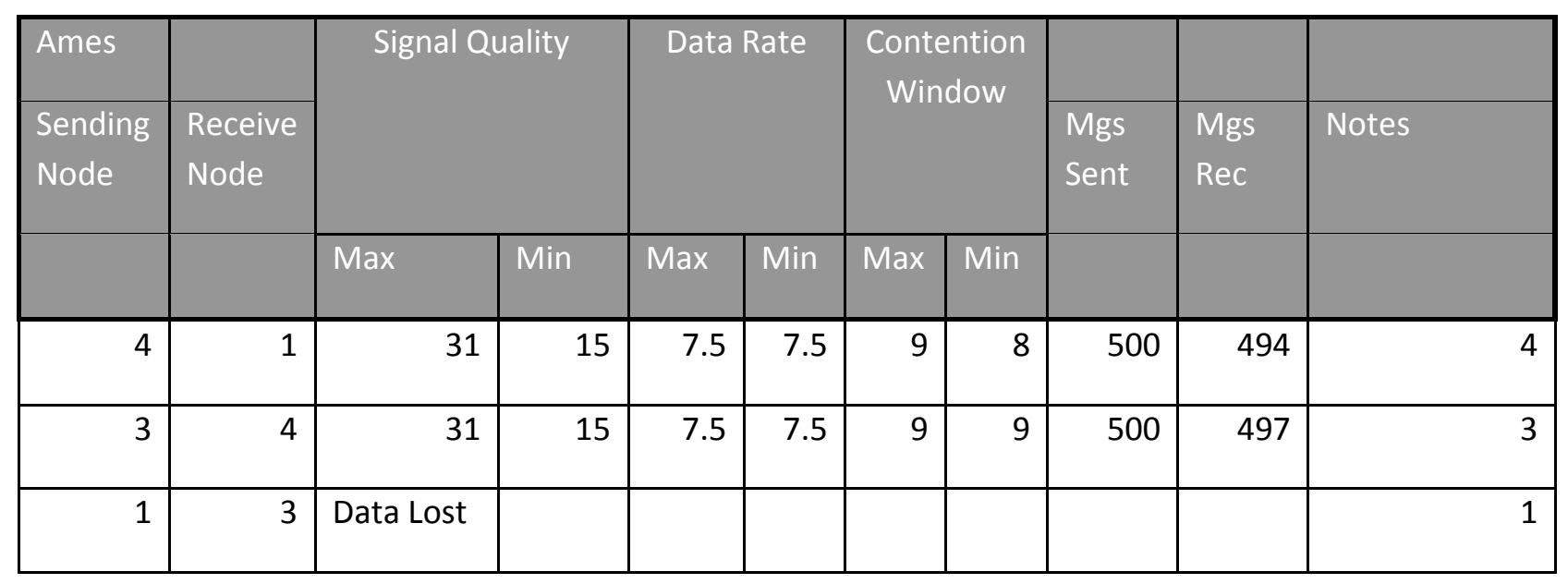

Table 7 - Ames Node 1 to Node 3 to Node 4

\begin{tabular}{|c|c|c|c|c|c|c|c|c|c|c|}
\hline Ames & & \multirow{3}{*}{\multicolumn{2}{|c|}{ Signal Quality }} & \multirow{3}{*}{\multicolumn{2}{|c|}{$\overline{\text { Data Rate }}$}} & \multirow{3}{*}{\multicolumn{2}{|c|}{$\begin{array}{l}\text { Contention } \\
\text { Window }\end{array}$}} & & & \\
\hline \multirow{3}{*}{$\begin{array}{l}\text { Sending } \\
\text { Node }\end{array}$} & \multirow{3}{*}{$\begin{array}{l}\text { Receive } \\
\text { Node }\end{array}$} & & & & & & & \multirow{3}{*}{$\begin{array}{l}\text { Mgs } \\
\text { Sent }\end{array}$} & \multirow{3}{*}{$\begin{array}{l}\text { Mgs } \\
\text { Rec }\end{array}$} & \multirow[t]{3}{*}{ Notes } \\
\hline & & & & & & & & & & \\
\hline & & $\operatorname{Max}$ & Min & $\operatorname{Max}$ & Min & $\operatorname{Max}$ & Min & & & \\
\hline $\begin{array}{l}\text { Node } 3 \\
\text { /Node } 4\end{array}$ & 1 & $31 / 31$ & $31 / 31$ & $5 / 5$ & $5 / 5$ & $22 / 16$ & $9 / 9$ & $\begin{array}{l}200 / \\
200\end{array}$ & $\begin{array}{l}282 / \\
198\end{array}$ & $\begin{array}{l}136 \text { relayed thru 3; } \\
1 \text { relayed thru } 4\end{array}$ \\
\hline Node 1 & 3 & $31 / 31$ & $31 / 30$ & $5 / 5$ & $5 / 5$ & $13 / 16$ & $9 / 9$ & $200 /$ & $198 /$ & No relays \\
\hline
\end{tabular}




\begin{tabular}{|l|l|l|l|l|l|l|l|l|l|l|}
\hline /Node 4 & & & & & & & & 200 & 199 & \\
\hline $\begin{array}{l}\text { Node 1 } \\
\text { Node 3 }\end{array}$ & 4 & $31 / 31$ & $31 / 31$ & $5 / 5$ & $5 / 5$ & $14 / 18$ & $9 / 9$ & $\begin{array}{l}200 / \\
200\end{array}$ & $\begin{array}{l}197 / \\
268\end{array}$ & $\begin{array}{l}2 \text { relayed thru 3; } \\
70 \text { relayed thru 1 }\end{array}$ \\
\hline
\end{tabular}

Table 8 - Ames All Nodes to All Nodes

\subsubsection{Urbandale Testing Results}

As before, Node 1 is the Network Coordinator, and Nodes 3 and 4 are the Remotes. Node 1 was placed in the basement near the power panel. Node 4 was placed in a second-floor bedroom furthest from the panel, connected to the same power phase as Node 1. Initially, Node 3 was connected to a circuit of the second phase of the panel feeding the outlets in the family room on the main floor. Connectivity from this initial Node 3 position was never established with the coordinating node or Node 4. Several other locations connected to the second phase of the panel also failed to connect to the network. Node 3 was moved to a main floor living room circuit connected to the same panel phase as Nodes $1 \& 4$ and immediately joined the network.

Details are shown in Table 9 - Table 12 below.

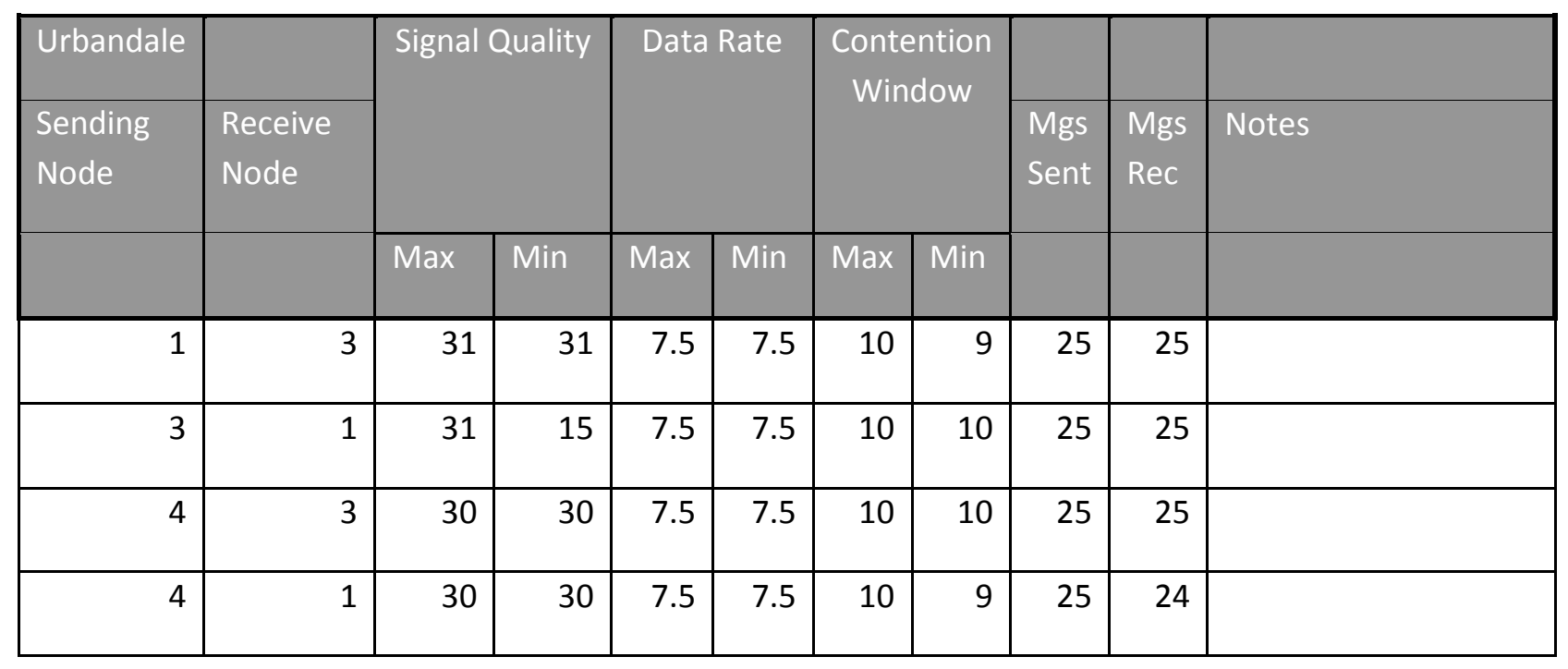

Table 9 - Urbandale Signal Node to Signal Node

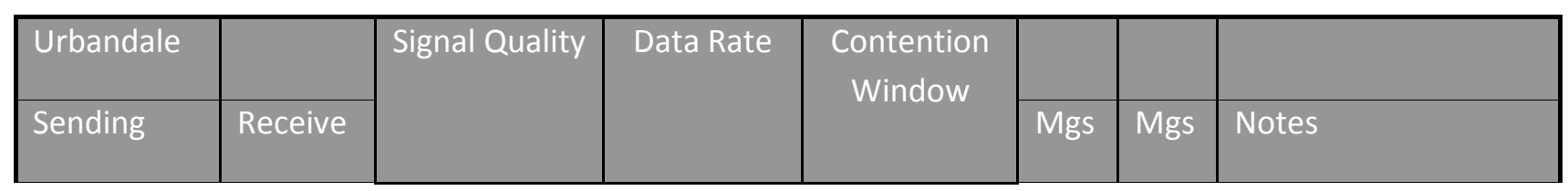




\begin{tabular}{|c|c|c|c|c|c|c|c|c|c|c|}
\hline Node & Node & & & & & & & Sent & $\operatorname{Rec}$ & \\
\hline & & Max & Min & $\operatorname{Max}$ & Min & Max & Min & & & \\
\hline 1 Broadcast & 3 & 31 & 31 & 5 & 5 & 11 & 11 & 25 & 21 & \\
\hline 3 Broadcast & 1 & 31 & 30 & 5 & 5 & 11 & 10 & 25 & 21 & 1 relayed thru 4 \\
\hline 4 Broadcast & 3 & 30 & 30 & 5 & 5 & 10 & 9 & 25 & 24 & \\
\hline 4 Broadcast & 1 & 30 & 30 & 5 & 5 & 10 & 9 & 25 & 24 & \\
\hline
\end{tabular}

Table 10 - Urbandale Signal Node to All Nodes 


\begin{tabular}{|c|c|c|c|c|c|c|c|c|c|c|}
\hline Urbandale & & \multirow{3}{*}{\multicolumn{2}{|c|}{ Signal Quality }} & \multirow{3}{*}{\multicolumn{2}{|c|}{$\overline{\text { Data Rate }}$}} & \multirow{3}{*}{\multicolumn{2}{|c|}{$\begin{array}{l}\text { Contention } \\
\text { Window }\end{array}$}} & & & \\
\hline \multirow{3}{*}{$\begin{array}{l}\text { Sending } \\
\text { Node }\end{array}$} & \multirow{3}{*}{$\begin{array}{l}\text { Receive } \\
\text { Node }\end{array}$} & & & & & & & Mgs & Mgs & Notes \\
\hline & & & & & & & & Sent & $\operatorname{Rec}$ & \\
\hline & & $\operatorname{Max}$ & Min & $\operatorname{Max}$ & Min & Max & Min & & & \\
\hline 4 & 1 & 30 & 30 & 7.5 & 7.5 & 9 & 9 & 200 & 200 & \\
\hline 3 & 4 & Data Lost & & & & & & & & \\
\hline 1 & 3 & 31 & 31 & 7.5 & 7.5 & 9 & 9 & 200 & 200 & \\
\hline
\end{tabular}

Table 11 - Urbandale Node 1 to Node 3 to Node 4

\begin{tabular}{|c|c|c|c|c|c|c|c|c|c|c|}
\hline Urbandale & & \multicolumn{2}{|c|}{ Signal Quality } & \multicolumn{2}{|c|}{ Data Rate } & \multicolumn{2}{|c|}{$\begin{array}{l}\text { Contention } \\
\text { Window }\end{array}$} & & & \\
\hline \multirow[t]{2}{*}{$\begin{array}{l}\text { Sending } \\
\text { Node }\end{array}$} & \multirow[t]{2}{*}{$\begin{array}{l}\text { Receive } \\
\text { Node }\end{array}$} & & & & & & & Mgs Sent & Mgs Rec & Notes \\
\hline & & Max & Min & Max & Min & Max & Min & & & \\
\hline $\begin{array}{l}\text { Node } 3 / \\
\text { Node } 4\end{array}$ & 1 & $31 / 31$ & $31 / 30$ & $5 / 5$ & $5 / 5$ & $12 / 12$ & $9 / 9$ & $200 / 200$ & $200 / 194$ & No relays \\
\hline $\begin{array}{l}\text { Node } 1 / \\
\text { Node } 4\end{array}$ & 3 & $31 / 31$ & $31 / 30$ & $5 / 5$ & $5 / 5$ & $11 / 12$ & $9 / 9$ & $200 / 200$ & $200 / 194$ & No relays \\
\hline
\end{tabular}

Table 12 - Urbandale All Nodes to All Nodes

\subsection{Conclusions}

Power line communications is a relatively mature communications medium, and the data rates required for Smart Grid communications will be far lower than that currently used for common home-automation PLC purposes like audio/visual streaming. Though this initial testing was limited and somewhat subjective, the general feeling is that PLC is a viable methodology for communications provided the location's installed wiring allows the signal to couple from one circuit phase to another where communication between device nodes is desired; otherwise a bridge device that couples the signal between circuit phases would be required. Where the information traffic is directly between individual nodes and the power meter, PLC would be acceptable. In areas where the phases are not coupled or where additional PLC traffic is not desired, using a wireless RF link to couple the phase via hybrid nodes might also be a possibility. 
PLC may also afford more physical security, on top of any software protocols, than a full wireless system because the power line can be shielded by conduit, and any unused outlet could be de-energized. Provided the power meter is equipped to transmit and receive the necessary signals, PLC could prove to be an effective platform for a simple and robust network for the installed non-smart appliance base. In terms of simplicity, in some of the basic usage cases the end user only needs to plug the device into a wall outlet to achieve communications.

The technical feasibility of successful PLC communications within the home is well established, although extra hardware to solve the communication-across-phases problem is often needed. As we expected, a second chipset would be added to handle this specialized medium, and the two chipsets would share data serially with one another. The objectives of this task have been satisfied. 


\section{Task 4 - Appliance Power Monitoring}

\subsection{Phase 1 Plan}

Our Task 4 drivers were, as stated in our Phase 1 proposal's project narrative:

“... new products that could be developed as a result of the proposed research .... include smart wall outlets, smart outlet power-monitoring adapters, smart load switches and smart remote electric rate indicators associated with the non-smart appliance."

"... we will explore the feasibility of using the same chipset to control the functions of monitoring the power used by the connected non-smart appliance and reporting either an energyuse profile or instantaneous energy-use values back to the utility."

"We will analyze the capability of the chipset to detect the voltage and current supplied through the outlet to the appliance, calculate the power and report the resulting power use of the nonsmart appliance back to the AMI via the communications link (wired or wireless). This will be calculated by measuring the peak of the AC voltage signal safely scaled down to a lower voltage level and by inputting the signal from a magnetic current sensor to the microprocessor-based chipset."

\subsection{Overview}

Currently, there is a growing interest in home energy usage information within US households. There are many examples of this, including the web applications of America's biggest business "superbrands", Google and Microsoft, with their "Google PowerMeter" and "Microsoft Hohm" offerings, respectively. Being software applications, though, these rely on other hardware to actually measure the household power use and send the data to their web-based applications.

At another level, many companies like Honeywell, White-Rodgers, and Canadian startup, Ecobee, have been working on Smart Thermostat products which essentially add wireless communication capabilities to the previous generation of programmable wall thermostats. This type of device could become a new gateway for a home-centric smart energy management system, having direct control of the home's major heating and cooling appliances, and the ability to communicate with other devices via the coming open Smart Energy standards.

One particularly interesting phenomenon surrounding appliance energy monitoring is the "Tweet-a-watt" do-it-yourself tweaking that has evolved around P3 International's Kill-A-Watt electricity usage monitor device. Basically, when plugged in between an appliance's power cord and the wall outlet, the Kill-A-Watt device measures and displays the electrical parameters associated with the appliance's power use. This product's standalone capability of reporting a consumer appliance's previously unknown energy consumption level, coupled with its affordable price and retail availability, made it a popular item for the early-adopting, eco-technical consumer. But as part of a "Greener Gadgets" design competition last year, someone proved that with a few technical functions added, it could broadcast its energy consumption data on the 
Internet via a Twitter account. Now there are "Tweet-a-watt" kits available for sale online with instructions for the home enthusiast who would like to add a Zigbee radio module to it and broadcast their appliance data to their free Google PowerMeter application, for example.

One of the challenges to measuring an individual appliance's energy consumption is accuracy. This challenge is compounded by two main issues: the wide range of appliance power consumption and the wide variation of power factor in appliances.

Wide range speaks to the fact that for a given appliance, its energy usage could range from very, very small standby power like $50 \mathrm{~mW}$ to very large amounts like over $5 \mathrm{~kW}$ with the heater on for an electric clothes dryer. Designing good measurement strategies at one extreme usually requires a different set of requirements than at the other extreme - and these extremes can easily vary by a factor of $1,000,000$ !

Power Factor is an efficiency ratio that tells how much real work can be accomplished by the watts used to drive the load (real power) compared to how many volts-amps must be delivered by the utility to support that same work (apparent power). Power Factors can be reduced from their ideal value of ' 1 ' by inductive or capacitive loads, which shift out-of-phase their voltage and current waveforms, and by loads such as switching power supplies, which can generate a non-sinusoidal current waveform. Designing an accurate measurement system for these types of variations requires either high-speed signal sampling or creative signal analysis algorithms or both.

It is appropriate, then, that one of our goals in Phase 1 was to determine the feasibility of adding good-accuracy, electrical parameter measurement capability to popular low-cost, low-power microcontrollers.

\subsection{Test Setup Overview}

Task 4 was to investigate and evaluate methods of measuring voltage and current, and using those measurements, to calculate power usage in its various forms and factors. The measurement method(s) design has the requirement of interfacing with the Analog-to-Digital (A-to-D) input ports of the Freescale and TI microcontroller-plus-RF-transceiver evaluation kits used in Task 1. The examples and discussions in this section will describe items in general terms that may not be ideal for one or both chipsets as presented here, but would require only minor changes in passive component values or adjustment of scalar values. This document covers only the gathering and processing of data and not how that data would be used or presented to the outside world.

\subsubsection{Voltage \& Current Measurement Methods}

Voltage measurements were relatively easy and direct. The microcontrollers in both evaluation kits have A-to-D inputs, and it is required only to scale the voltage from line level to the acceptable range of the A-to-D ports. 
Current measurements are more involved. All methods convert the current level to a proportional voltage. The traditional method for measuring AC line current is to place a ferrite core, toroidal pick-up coil around the current-carrying wire. A second method is to use a knownvalue fixed resistor in series with the load (termed a Sense Resistor [RS]) and measure the voltages on both side of the resistance. The differential of these voltages divided by the value of the RS results in the current level. A more recent method has emerged based on a Hall Effect sensor packaged in a surface-mount chip.

Methods considered and compared for measuring the current drawn by an appliance include:

\subsubsection{Toroidal}

- Bulky, could introduce phase shift into reading

- Not directly connected to power circuit

- Can require special knowledge to install

\subsubsection{Sense Resistor - Selected for Development}

- Mostly used for DC systems, small resistance limits system resolution, large resistance could heat and/or increase power usage

- Inexpensive, takes measurement directly from circuit

\subsubsection{IC-based Hall Effect Sensor}

- Expensive compared to RS

- Not directly coupled, output is scaled to microprocessor levels

\subsubsection{Hardware Examples - Sense Resistor}

In Figure 10 below is an example of a circuit for scaling and conditioning voltage from either side of a sense resistor (R16). The circuit also shows a simple AC to DC +5 volt supply that draws power from the incoming line, L1. The measured voltages from Q1 [Vhi(uP)] and Q2 [Vlow(uP)] are used to calculate current and power. R48 \& R49 represent the inputs to A-to-Ds. The line level voltages are scaled down to a safe level, and the bias network on the transistor gives them a positive offset so the A-to-Ds see voltages between 0 and +5 VDC. 


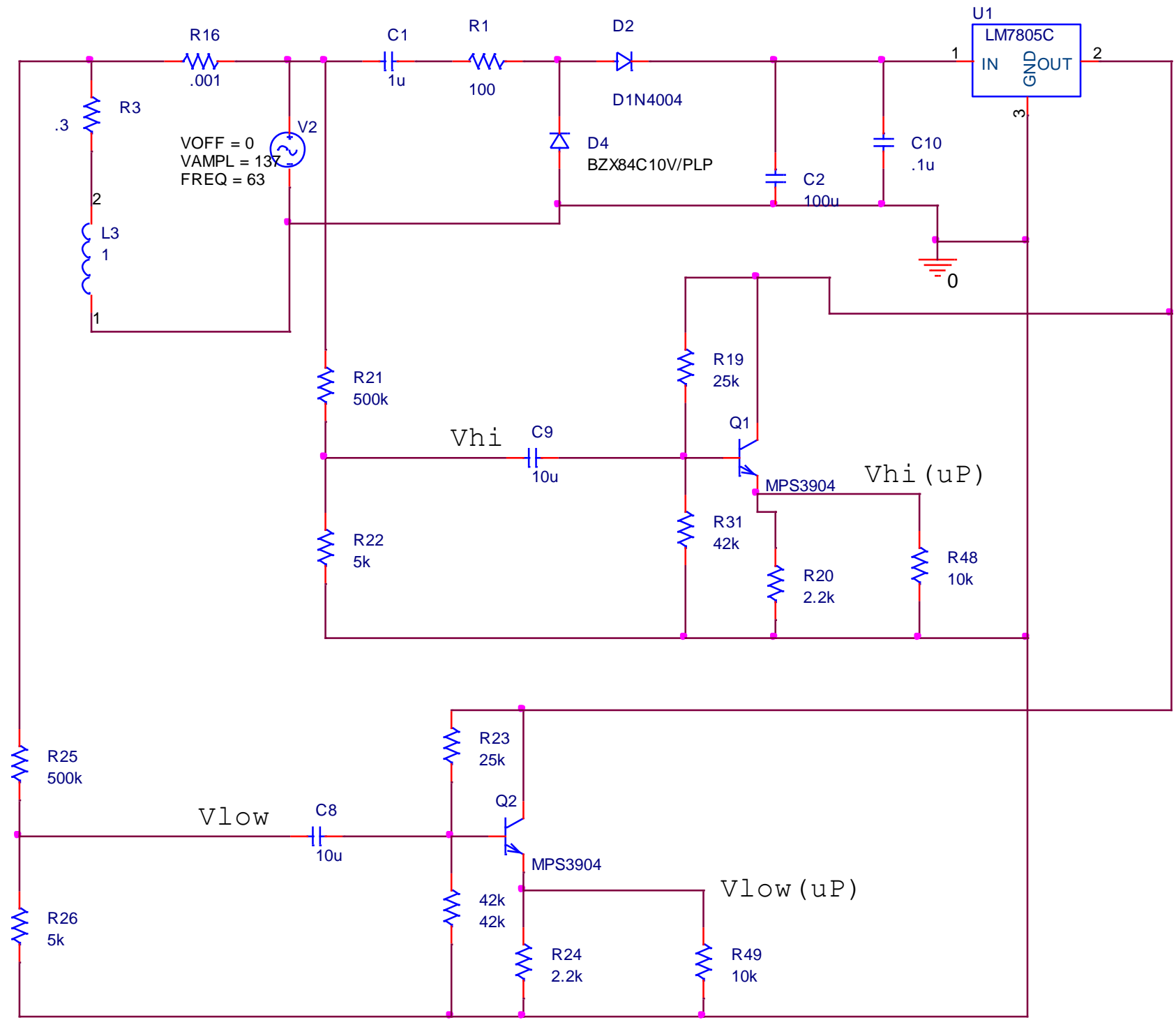

Figure 10: Prototype Sense/DC Power Circuit

\subsubsection{Power Calculation Algorithm}

This power calculation algorithm uses the voltage level measured at the input of the load connection and the sensed current to the load for its incoming data. If a sense resistor is used, a preceding step is needed, using the difference between Vhi and Vlow to determine the current draw. The algorithm samples, recording data approximately every other cycle, and requires slightly more than one cycle to actually calculate values.

[Note: The algorithm as shown here is based on bi-polar data. In practice, the microcontroller will most likely have positive-only A-to-D inputs, and additional processing will need to be done 
to account for the required DC offset added to the signals. "Deadbands" around the trip points will also need to be added for de-bounce purposes.]

The algorithm that follows in Figures 11 and 12 is based on trip points that set software flags which control data collection and processing.

Initially all flags are set False. The voltage signal is monitored until its level exceeds a set point. This sets the voltage flag Vflg and the RMSflg to True, and data collection is started. As the voltage signal continues and returns to a level below the set point, Vflg is set to False and the voltage reset flag Vfrs is set True. As long as RMSflg is True, data is collected and initial processing is done.

Initial Processing:

- Accumulation of the squares of the voltage data points

- Accumulation of the squares of the amperage data points

- Accumulation of the number of data points

- Accumulation of the squares of the instantaneous power (V x I)

- Partial integration of the instantaneous power

- Maximum Voltage and Maximum Current are tracked

Once the voltage signal exceeds the voltage setpoint for the second time, indicating the end of a full cycle, data collection stops, and data processing begins.

\section{Processed value:}

- Vrms

The accumulated squares of the voltage are divided by the number of accumulated data points, and the square root of the value is calculated with an iterative sub-routine.

- Irms

The accumulated squares of the current are divided by the number of accumulated data points, and the square root of the value is calculated with an iterative sub-routine.

- Watts (Average Power)

The partial integral value for instantaneous power is divided the number of accumulated data points.

- Volt-Amps

Vrms and Irms are multiplied together.

\section{- Power Factor}

Watts are divided by Volt-Amps. 
- Frequency

The number of accumulated data points is multiplied by the sample rate of the data and inverted.

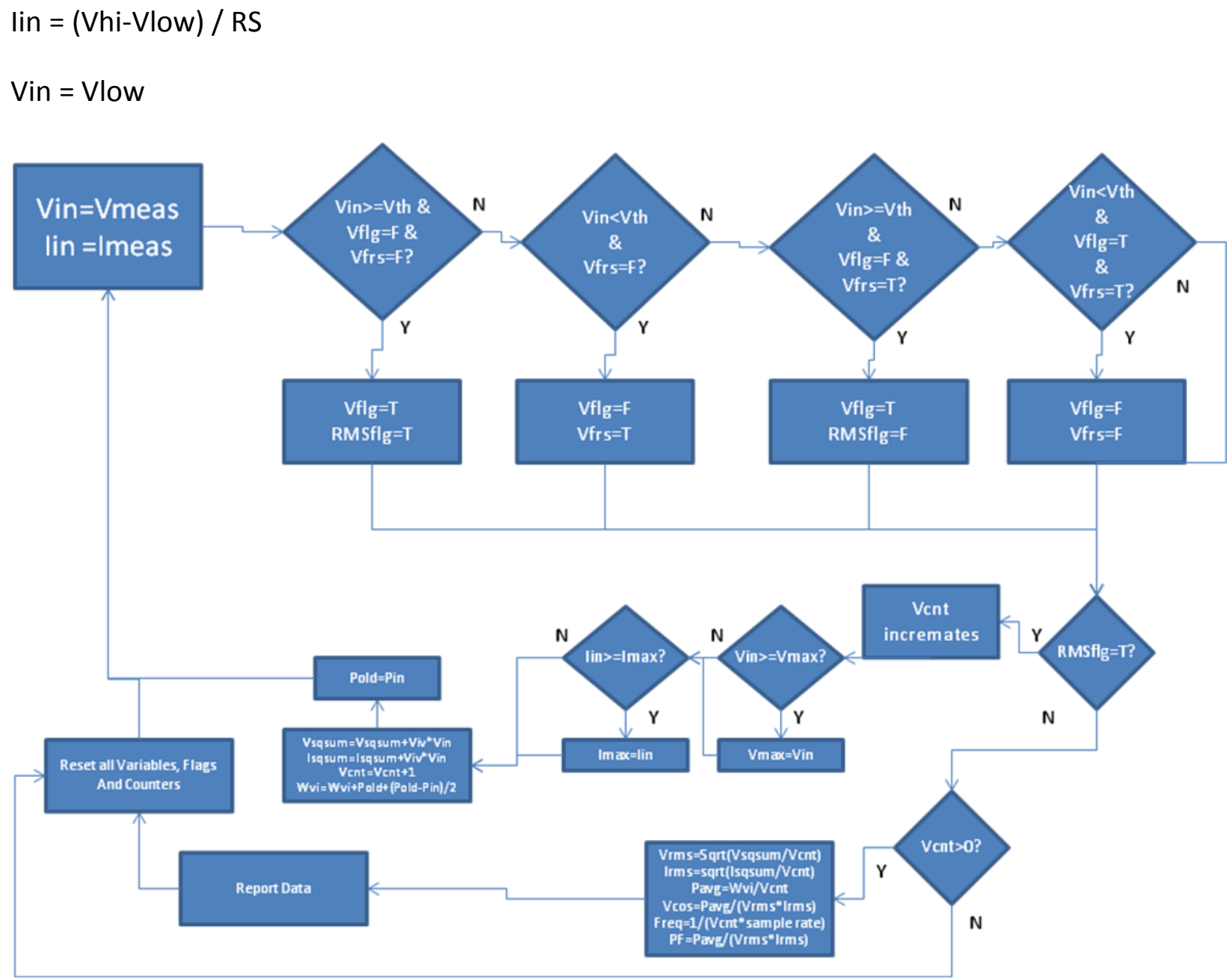

Figure 11: Algorithm Flow Chart 


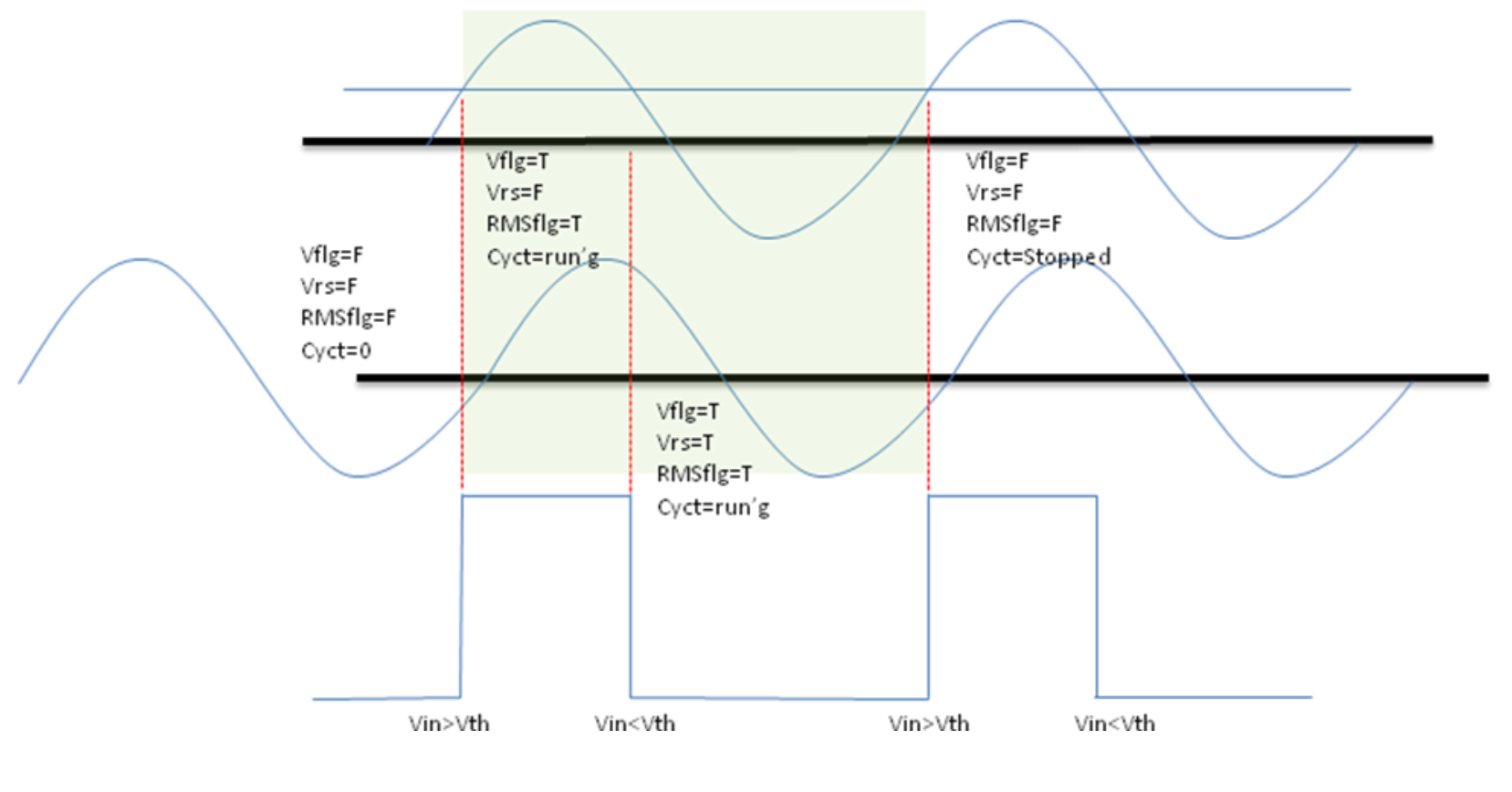

Figure 12: Algorithm Trip Points

\subsubsection{Power Calculation Test Program}

Figure 13 shows the algorithm implemented as a power calculation test program in Microsoft Excel VBA. 


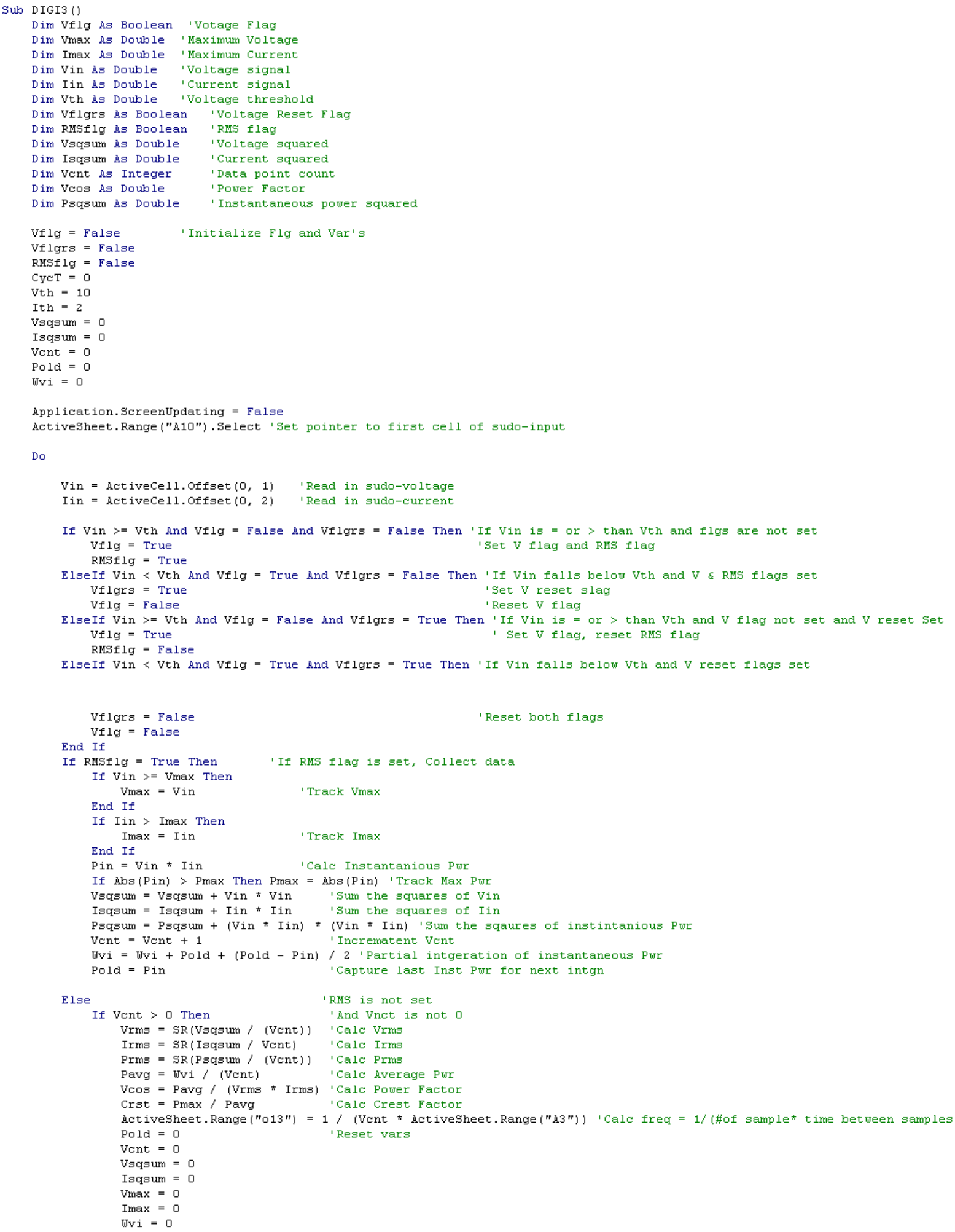




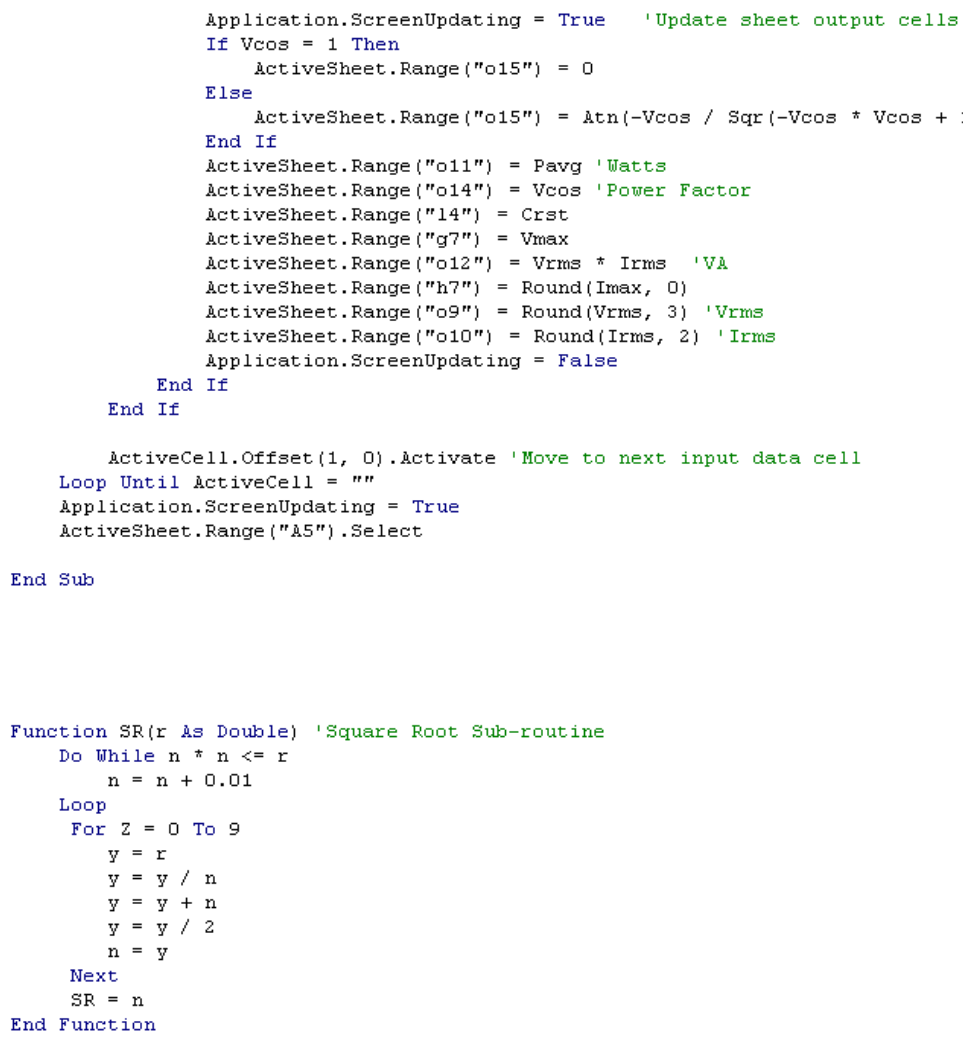

Figure 13: Test Program

\subsubsection{Test Measurement Hardware}

Prototypes of the circuit as shown above were created and were successful in scaling and delivering an adequate signal for a microcontroller's A-to-D inputs; however, for the microcontroller to accurately resolve the voltage drop for 1 ampere across the $.001 \mathrm{ohm}$ shunt requires 24-bit resolution or better. For this task, we acquired several versions of the GMW CSA-1V, IC-based current sensor chips mounted on evaluations boards that required only +5 VDC power and output a voltage proportional to the sensed current. One of the sensor evaluation boards was attached directly over one of the AC traces of the prototype boards and fed power from the 5 VDC rail of the prototype board. Scaled output from the CSA-1V and the Vlow signal from the prototype board were fed to individual channels of two multi-channel oscilloscopes. Both scopes were used to capture the voltage level at the input of the load and the voltage proportional to the load current from the CSA-1V development board. One scope, an Agilent Model 54825A, was set to sample at a rate of $10 \mathrm{kHz}$. The second, a Tektronix Model TDS3032B, was set to sample at a rate of $25 \mathrm{kHz}$. The different sampling rates were used to generate data to explore the algorithm's sensitivity to the sample rate. 
In addition, two commercially available power measurement devices were acquired and used in testing as examples of off-the-shelf technology: an instrument-grade, calibrated Voltech PM1000+ Power Meter, and a consumer-grade P3 International Kill-a-Watt ${ }^{\mathrm{TM}}$ EZ. The PM1000+ data was also used as the baseline for accuracy comparisons.
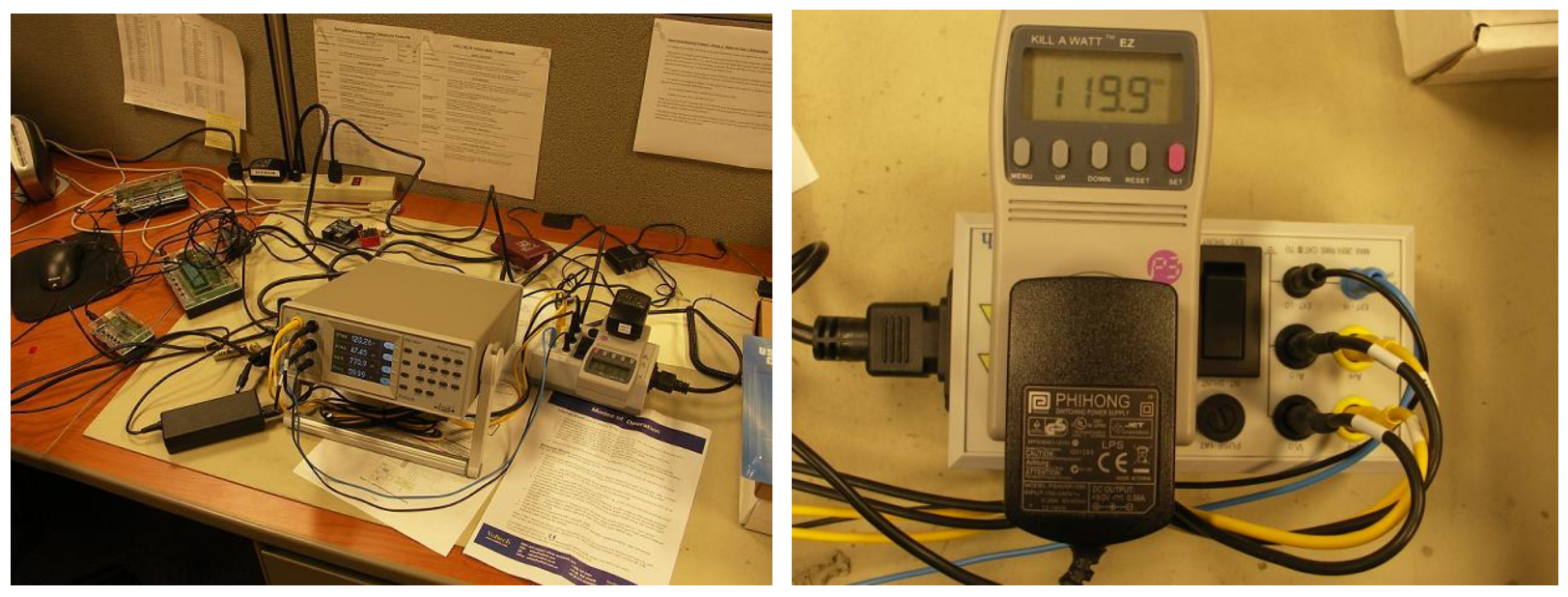

Figure 14: Power Measurement Devices - Voltech (left) and Kill-a-Watt (right)

\subsubsection{Test Loads}

Two different types of electrical loads were used: an Alpha Fit Gun 3 heat gun (with a singlephase induction fan motor and a $1200 \mathrm{~W}$ heating element) and a Whirlpool commercial frontload washing machine (with drain pump, water valve solenoids, and a multi-phase motor).

The heat gun is a good resistive load example because the power draw by the motor is much less than that of its heating element. The gun has two heat settings, $1200 \mathrm{~W}$ and $600 \mathrm{~W}$, and adjusts the power usage by clipping half the input voltage wave on the $600 \mathrm{~W}$ setting.

The washer machine's main power user is its drive motor: a 3-phase, Controlled Induction Motor (CIM). It is controlled by a voltage inverter-based drive circuit which takes the incoming singlephase power and converts it to 3-phase, PWM drive signals.

Both loads were powered separately through each of the three measurement devices.

Measurements were taken with the heat gun running on both heat settings, and the washing machine data was taken with the machine in a steady, high-speed spin.

\subsection{Testing Results}

\subsubsection{Parameter Measurement Data}

Vrms, Irms, Watts, VA, Freq and Power Factor were read and recorded from the PM1000+ and Kill-a-Watt displays and tabulated. 
The scope traces from our prototype electronic measuring circuit were recorded and copied to an Excel workbook, scaled to a representative volume and run through the VBA version of the algorithm. Note that the scalar values were rough estimates, and the signal had no filtering to eliminate high frequency noise. The results and comparison of the three measurement devices are shown below.

\subsubsection{Heat Gun Testing Results}

\begin{tabular}{|l|c|c|c|c|c|}
\hline Measurement & PM1000+ & $\begin{array}{l}\text { Kill A Watt } \\
\text { EZ }\end{array}$ & $\begin{array}{l}\text { Variance } \\
\text { from } \\
\text { PM1000+ }\end{array}$ & $\begin{array}{l}\text { Prototype } \\
\text { Board }\end{array}$ & $\begin{array}{l}\text { Variance } \\
\text { from } \\
\text { PM1000+ }\end{array}$ \\
\hline Vrms & 114.60 & 113.55 & $-0.92 \%$ & 113.53 & $-0.94 \%$ \\
\hline Irms & 9.82 & 9.72 & $-1.02 \%$ & 9.95 & $1.32 \%$ \\
\hline Watts & 1122 & 1107 & $-1.34 \%$ & 1125 & $0.25 \%$ \\
\hline VA & 1126 & 1110 & $-1.42 \%$ & 1129 & $0.28 \%$ \\
\hline Freq (Hz) & 60.0 & 60.0 & $0.00 \%$ & 59.9 & $-0.20 \%$ \\
\hline Power Factor & 1.000 & 1.000 & $0.00 \%$ & 0.996 & $-0.39 \%$ \\
\hline
\end{tabular}

Table 13 - Heat Gun @ 1200 Watt Setting 


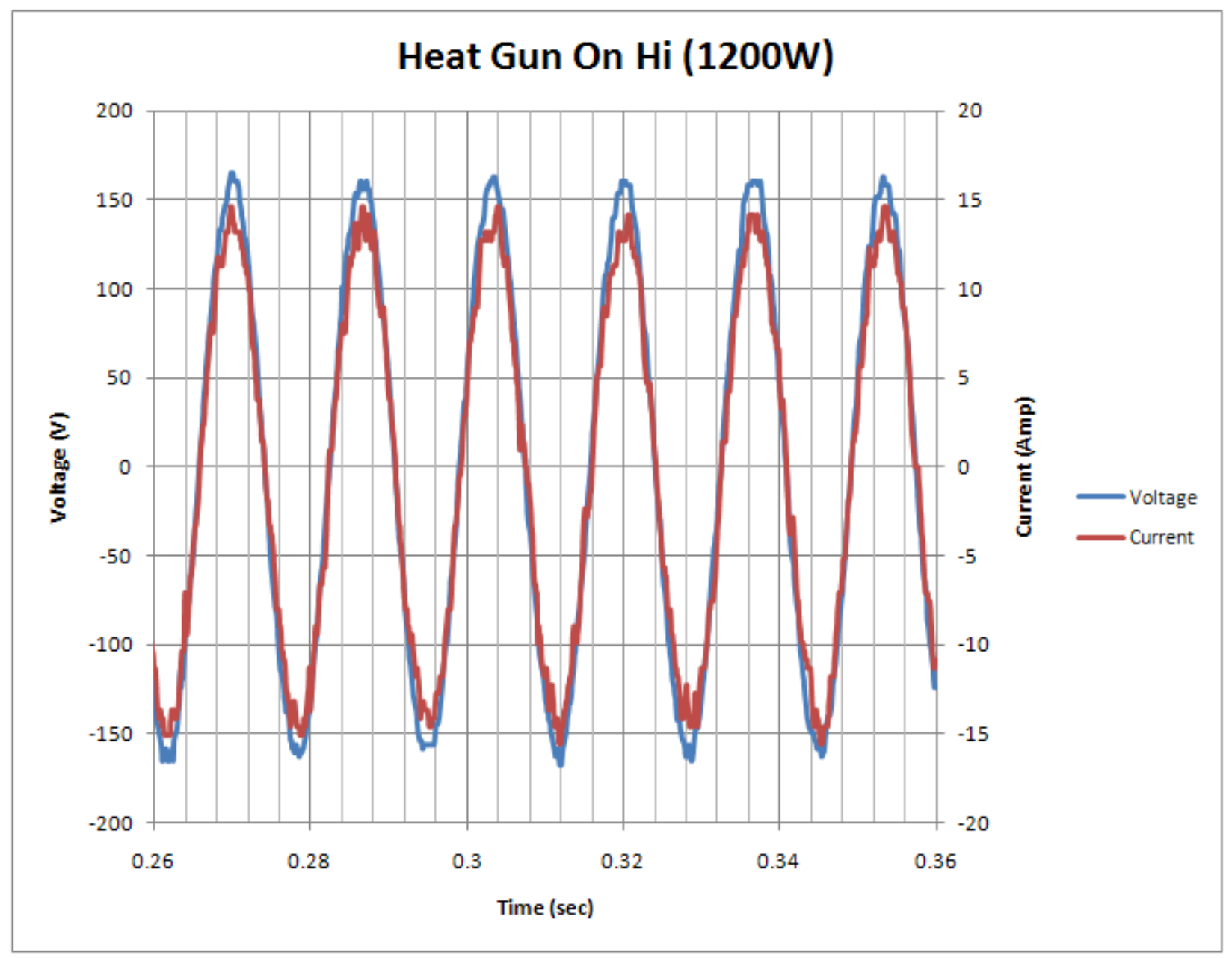

Figure 15: Voltage \& Current @ 1200 Watt Setting 


\begin{tabular}{|l|c|c|c|c|c|}
\hline Measurement & PM1000+ & \multicolumn{1}{l|}{$\begin{array}{l}\text { Kill A Watt } \\
\text { EZ }\end{array}$} & $\begin{array}{l}\text { Variance } \\
\text { from } \\
\text { PM1000+ }\end{array}$ & $\begin{array}{l}\text { Prototype } \\
\text { Board }\end{array}$ & $\begin{array}{l}\text { Variance } \\
\text { from } \\
\text { PM1000+ }\end{array}$ \\
\hline Vrms & 116.30 & 116.10 & $-0.17 \%$ & 116.03 & $-0.23 \%$ \\
\hline Irms & 7.20 & 7.15 & $-0.69 \%$ & 7.02 & $-2.50 \%$ \\
\hline Watts & 579 & 571 & $-1.38 \%$ & 573 & $-1.11 \%$ \\
\hline VA & 836 & 829 & $-0.84 \%$ & 814 & $-2.57 \%$ \\
\hline Freq (Hz) & 59.9 & 60.0 & $0.17 \%$ & 59.9 & $-0.03 \%$ \\
\hline Power Factor & 0.690 & 0.689 & $-0.14 \%$ & 0.703 & $1.88 \%$ \\
\hline
\end{tabular}

Table 14 - Heat Gun @ 600 Watt Setting 


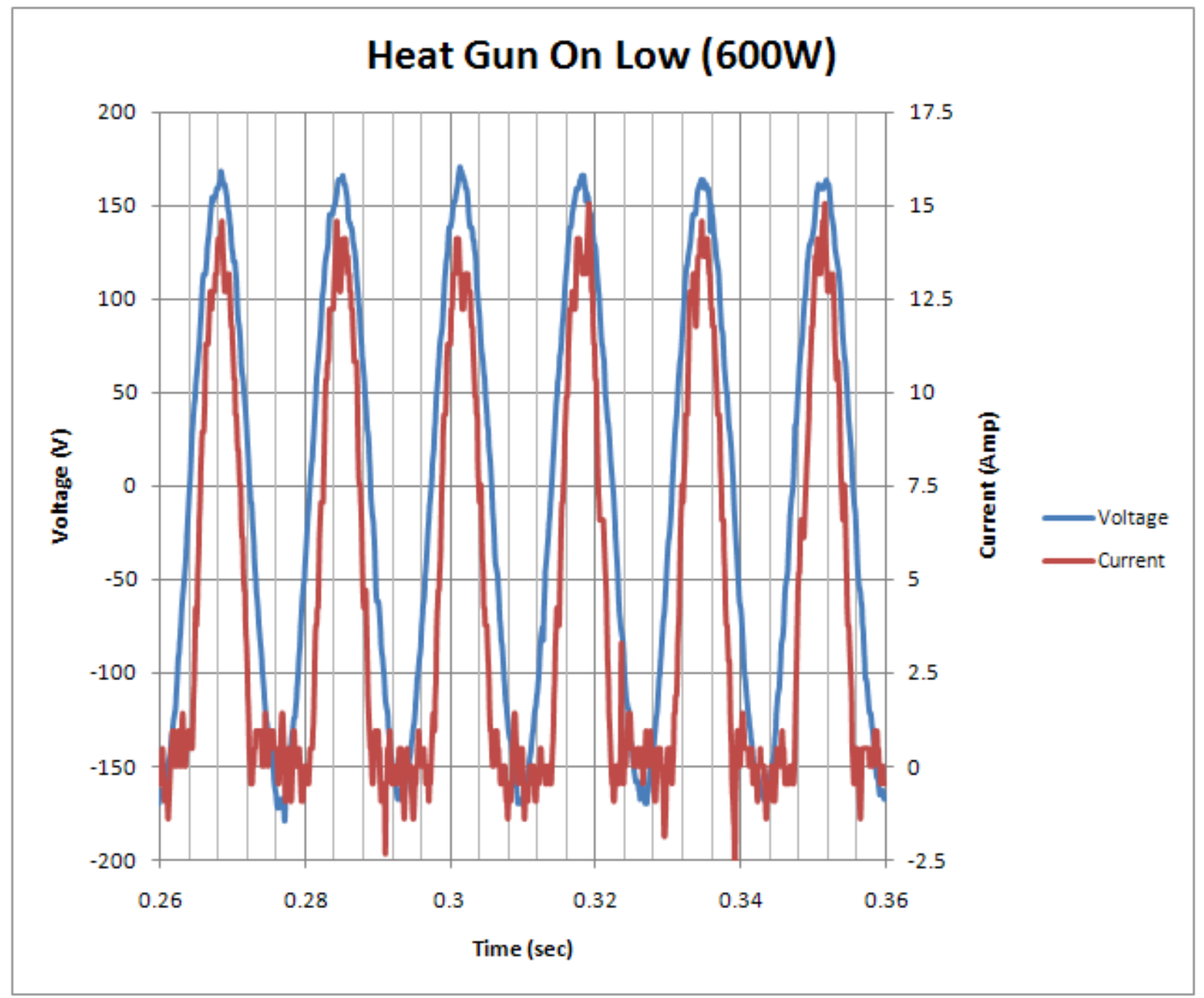

Figure 16: Heat Gun @ 600 Watt Setting

\subsubsection{Front-load Washing Machine Results}

\begin{tabular}{|l|c|c|c|c|c|}
\hline Measurement & PM1000+ & $\begin{array}{l}\text { Kill A Watt } \\
\text { EZ }\end{array}$ & $\begin{array}{l}\text { Variance } \\
\text { from } \\
\text { PM1000+ }\end{array}$ & $\begin{array}{l}\text { Prototype } \\
\text { Board 10 kHz } \\
\text { Sample Rate }\end{array}$ & $\begin{array}{l}\text { Variance } \\
\text { from } \\
\text { PM1000+ }\end{array}$ \\
\hline Vrms & 118.77 & 119.3 & $0.45 \%$ & 119.19 & $0.35 \%$ \\
\hline Irms & 3 & 3 & $0.00 \%$ & 2.99 & $-0.33 \%$ \\
\hline Watts & 217 & 217 & $0.00 \%$ & 207 & $-4.52 \%$ \\
\hline
\end{tabular}




\begin{tabular}{|l|c|c|c|c|c|}
\hline VA & 345 & 359 & $4.06 \%$ & 357 & $3.42 \%$ \\
\hline Freq (Hz) & 59.97 & 59.9 & $-0.12 \%$ & 60.24 & $0.45 \%$ \\
\hline Power Factor & 0.613 & 0.6 & $-2.12 \%$ & 0.58 & $-5.28 \%$ \\
\hline
\end{tabular}

Table 15 - Washer Run 1

\begin{tabular}{|l|c|c|c|c|c|}
\hline Measurement & PM1000+ & $\begin{array}{l}\text { Prototype } \\
\text { Board 10 kHz } \\
\text { Sample Rate }\end{array}$ & $\begin{array}{l}\text { Variance } \\
\text { from } \\
\text { PM1000+ }\end{array}$ & $\begin{array}{l}\text { Prototype } \\
\text { Board 25 kHz } \\
\text { Sample Rate }\end{array}$ & $\begin{array}{l}\text { Variance } \\
\text { from } \\
\text { PM1000+ }\end{array}$ \\
\hline Vrms & 118.6 & 118.51 & $-0.07 \%$ & 118.76 & $0.14 \%$ \\
\hline Irms & 2.95 & 3.00 & $1.69 \%$ & 3.00 & $1.69 \%$ \\
\hline Watts & 214 & 208.13 & $-2.74 \%$ & 214.00 & $0.00 \%$ \\
\hline VA & 349.4 & 355.38 & $1.71 \%$ & 356.53 & $2.04 \%$ \\
\hline Freq (Hz) & 60 & 59.95 & $-0.08 \%$ & 60.05 & $0.09 \%$ \\
\hline Power Factor & 0.614 & 0.59 & $-4.62 \%$ & 0.60 & $-2.24 \%$ \\
\hline
\end{tabular}

Table 16 - Washer Run 2 


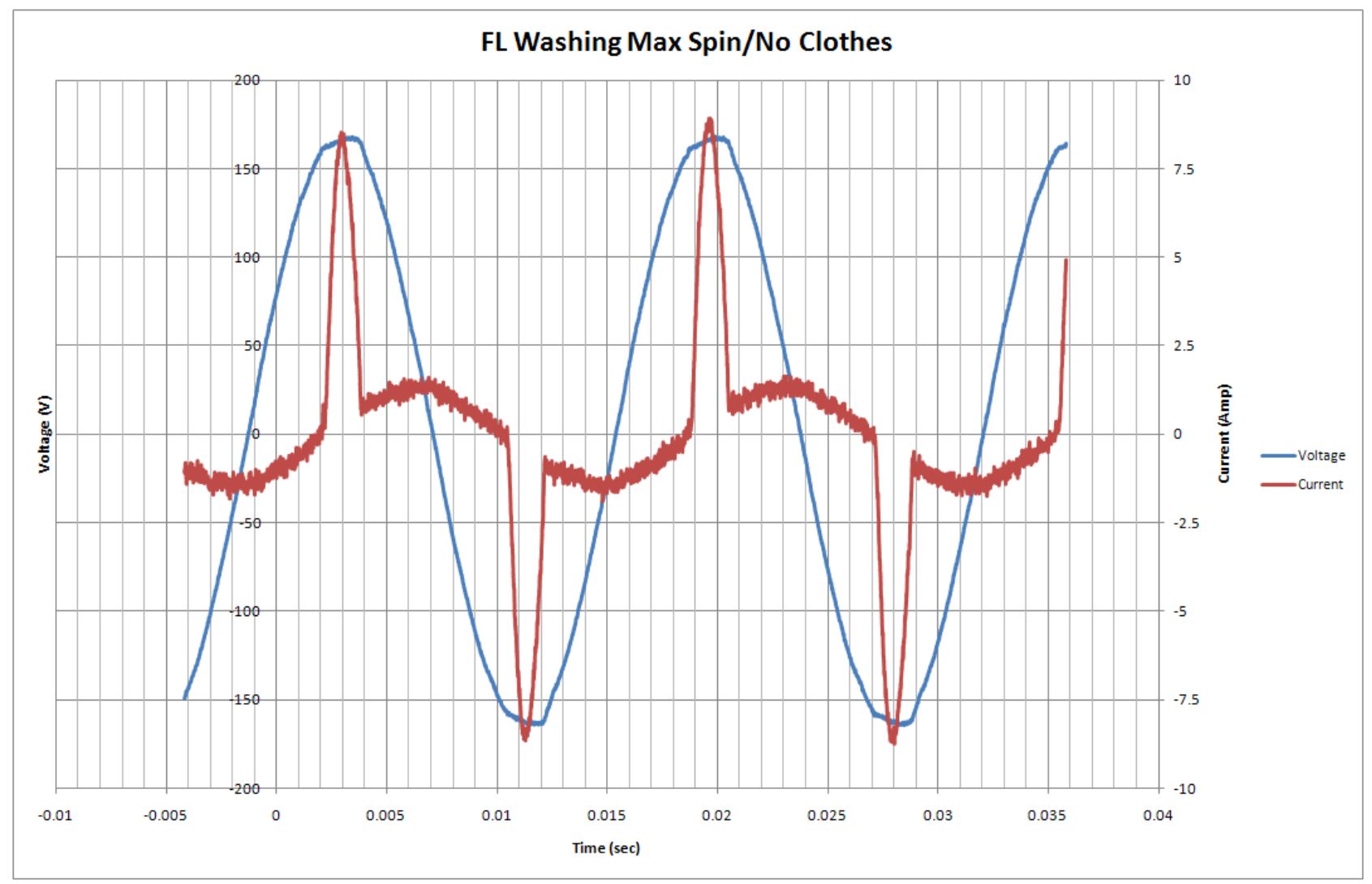

Figure 17: Washing Machine - High Speed Spin

\subsection{Conclusions}

Review of the data above shows there is no set of perfectly correlated numbers; each device differed in at least one measurement for each test run. Even the selected benchmark system, the Voltech PM1000+, seems to have an unknown issue in calculating VA given that several of the VA values are not the product of the Vrms and Irms values, as expected. (This is something to investigate further and understand in Phase 2.) The Kill A Watt ${ }^{\mathrm{TM}}$ EZ's power factor appears to correlate better the closer the current's waveform approximates a sine wave. Our low-cost prototype's correlation with the PM1000+ is, in general, less than that of the Kill A Watt ${ }^{\mathrm{TM}} \mathrm{EZ}$, but in some cases our prototype and the Kill A Watt ${ }^{\mathrm{TM}}$ agree, yet differ from the baseline meter.

Even though the Phase 1 test conditions lacked input power regulation and the prototype boards lacked filtering, the general performance of our prototype concept was very positive. The data generated with our test boards provided viable input to test the basic power measurement algorithm and confirm its core functions. In Phase 2, we plan to make further improvements in our low-cost, but sufficiently accurate, power measurement system. 


\section{Task 5 - Appliance Load Control}

\subsection{Phase 1 Plan}

Our Task 5 drivers were, as stated in our Phase 1 proposal's project narrative:

"... tests have been run with non-smart appliances including electric water heaters which were cycled off during critical or peak capacity periods by the sensing and load control boxes installed by a professional technician."

"The current state of the art for implementing smart control of non-smart appliances is an expensive proposition initiated by the utility provider, who then attempts to sign-up the customer by offering a small monthly rebate in return for access to and control of the targeted appliance. In terms of both dollars and 'hassle', the costliness of this approach - an approach which requires substantial advertising by the utility, industrial load control modules and communications hardware, a smart electrical meter, professional installation services, and scheduled access to the consumer's home - means that only the most power-hungry, hard-wired electricity-consuming appliances are viable candidates, typically a central air conditioner unit or an electric water heater.

“Appliance's of the 'persistent-use' type are also good candidates for being de-energized in response to a 'critical curtailment' signal that might be received from a utility in response to an urgent power supply situation. In some cases a minimum delay should be provided before the appliance is powered again, something the smart controller should easily handle."

"... new products that could be developed as a result of the proposed research ... include smart wall outlets, smart outlet power-monitoring adapters, smart load switches ..."

"We will explore whether the same chipset can safely and effectively be coupled to control devices capable of switching up to 30-Amp loads for disabling power to a connected household appliance. This satisfies the time-of-use shifting means required for 'persistent-use' appliance types and becomes ideal if it could be accomplished in a fully integrated smart product such as a new smart wall outlet."

\subsection{Overview}

The present view of when a 'peak electricity demand' condition is likely to occur seems fairly simple and predictable: humid day ... high temperature ... afternoon. This allows for easy firstgeneration solutions for peak avoidance to be somewhat managed by the energy-conscious residential consumer, who could be both willing and able to:

- reduce air conditioner use during the heat of the day

- turn off unnecessary lights throughout the daylight hours

- $\quad$ shift supper meal preparations to a later hour 
- delay dishwasher startup until later in the night

But this paradigm of successful peak demand avoidance will not necessarily be helpful in the future, as illustrated by the following quote reported in the Houston Business Journal (Friday, February 29, 2008) and referenced on the DOE's Office of Energy Delivery and Energy Reliability website:

"An abrupt loss of 1,200 megawatts of wind energy production on Feb. 26 [2008] caught the Electric Reliability Council of Texas Inc. by surprise and forced it to declare emergency conditions underscores a critical policy issue, according to a key industry official.

ERCOT said the sharp drop in production during a three-hour period - while overall electricity loads were increasing - threatened the stability of the power grid and could have caused rolling blackouts.

David Crane, President and CEO of New Jersey-based NRG Energy Inc., said the incident underscores the most critical energy policy issue facing the power industry.

'If a system can go unstable in the winter because 1,500 MW of expected wind turns into $400 \mathrm{MW}$ wind and then fossil has to scramble to come online - and several of our plants had to scramble to fill the gap - that's a big issue and there's going to be a big debate,' Crane said."

This emphasizes that fact that our new paradigm for interaction of home appliances with the Smart Grid has to take into account not only sometimes-predictable peak electricity demand, but also unpredictable peaks and valleys in the electricity supply: new renewable energy sources like wind and solar produce new dynamics in the supply of energy - wind speed can change unpredictably at times, and solar can be reduced in half by unpredictable clouds or reduced even more by sudden (and maybe prolonged) airborne smoke and/or ash.

Furthermore, some energy service providers will not only be using various Demand Response communications just to encourage consumers to reduce their electricity use during certain dynamic time periods (to lower the peaks), they will also be using various Dynamic Pricing programs that aim to correspondingly increase electricity usage by offering lowest rates during other dynamic time periods (to raise the valleys) - and inside the home, only new, smart load controllers will be able to help the millions of non-smart appliances participate in those programs. 
Residential consumers won't always be able to respond adequately to their utilities provider's situation unless their appliances are supported by machine-to-machine communications. As stated by the founder of GreenPeak Technologies, Cees Links (Remote Magazine, October/November 2008):

"The first wireless wave is generally considered to be voice ... person-to-person. The second wireless wave was wireless data ... computer-to-computer. The third wave of wireless takes communications to the next step, connecting machines to machines ... no longer do you need a human in the middle, or a computer. Today there are several available proprietary protocols that are promoted by individual companies. But to really accelerate the acceptance of the third wave of wireless, we need industry standards."

That last statement underscores why we appreciate the ongoing efforts of NIST in gathering the standards-making communities together to speed up the creation of workable standards for Smart Grid implementation, which inside the home (and closest to the appliance) looks to be the coming Zigbee+HomePlug Smart Energy 2.0 communications standard.

Despite strong motivation by all constituents to maintain backwards compatibility with existing protocols (including Zigbee Smart Energy 1.0 and HomePlug 1.0 protocols), this seems unlikely to happen. Historically, even the Zigbee and HomePlug alliances, separately, were not able to keep their latest versions (Zigbee Pro 2007 and HomePlug AV, respectively) backwards compatible with their earlier versions because of the fundamental goals and requirements of the latter systems. Similarly, we should expect that new Smart Grid interconnection goals and requirements will push new security, communications, pricing and cross-functionality features which will cause the emerging Smart Energy 2.0 standard to move beyond the capabilities of any currently available "smart" devices. Quoting now from the Zigbee Alliance's Smart Energy webpage:

"ZigBee Smart Energy version 2.0 will be IP-based and offer a variety of new features. Given the important role ZigBee Smart Energy plays in the Smart Grid, the ZigBee Alliance is taking unprecedented steps for an open organization engaged in standards development."

In summary, it appears that every existing residential communications device for smart energy management is one step ahead of its time as far as compatibility with the coming, Smart Energy 2.0 standard and the corresponding Advanced Metering Infrastructure (AMI). More effort needs to be made now in helping to finish the creation of the Smart Energy 2.0 standard in a way that supports the needs of the various levels of home-centered smart devices, and more investment needs to be made now in the development of products that will be compliant with the new standard - including some new "multilingual" products that can bridge the communications gap between the new and old generations. 
Turning to the appliances now, unless and until the typical 'persistent-use' appliance (one that runs continually in the background unattended, such as a dehumidifier, pool pump, or deep freezer) is mated with a controllable power-switching device sized adequately for its load conditions, there can be no meaningful adaptation of its energy consumption in response to temporary energy supply conditions.

These 'persistent-use' appliances can be easily forgotten even in an energy-aware home because:

- they are often located outside of the normal traffic path in a home: out-of-sight, outof-mind

- though major contributors to the "baseline" energy consumption of home, they are not revealed by an obvious spike in energy usage at a particular time of the day

- they are not easily managed manually by a simple change in consumer habits; and often they do not even have electronic controls or features

On the other hand, these appliances should be major candidates to the energy reductions goals of home because:

- they are always running, so even if ranking lower than other appliances in peak energy consumption, they can be among the highest users on a monthly energy consumption basis

They are also good candidates for being served by new smart devices designed to control them because:

- they are often older, longer-lived, and less energy efficient (yielding greater energy saving potential)

- they are not as likely to have smart models designed to replace them at similar cost to the consumer (the major appliance manufacturers seem mainly focused on adding smarts to their existing electronically-controlled 'process-oriented' models)

- they can typically be cycled while unattended without adverse consequence (suitable for automated control)

- they often require lower peak switching currents than some of the 'process-oriented' appliance types

\subsection{Load Control Research Summary}

The primary power switching concepts can broadly be categorized, as detailed below, into two primary groups: Electro-mechanical Relays and Solid State Thyristors. 


\subsubsection{Electro-mechanical Relays}

A relay is similar to a switch. It turns ON or OFF an electrical load such as a light or an appliance. It has two primary parts - the coil and the contacts. The coil is a spool of wire with a core that is mechanically coupled to the electrical contacts that are connected to the load. When the coil is energized, the mechanical coupling moves and causes the electrical contact to either close or open, thereby controlling the load. The electrical contacts are sized according to the amount of electrical current passing through the load.

Some advantages of relays are:

1) The coil (or control signal) is isolated from the relay contacts switching the load.

2) The coil can be designed to operate at a variety of different voltages.

3) The contact resistance and resulting heat of relay contacts is very low and is far less than a thyristor.

4) When a relay coil is de-energized, the load is normally off.

5) When the relay contacts are open, there is normally no load voltage or current, making them a good choice for "fail safe" applications.

6) Relays are normally less expensive than comparable thyristors for larger loads.

Some disadvantages of relays are:

1) The coil may draw a substantial amount of current - depending on the size of the load contacts.

2) The physical size of power relays can be quite large.

3) Relay coils can produce a fair amount of heat and normally need to be energized to operate the load.

\subsubsection{Solid State Thyristors}

A thyristor is a solid state switch and is typically configured as either an SCR or a Triac. These devices typically have three leads - the anode, the cathode and the gate. The load and voltage source is between the anode and cathode. The control signal is connected between the gate and the cathode. When SCRs or Triacs are turned ON, there is a small voltage drop across the device which produces heat. This heat must be dissipated, typically through a heat sink, in order for the device to function properly.

\section{1) SCRs:}

When a signal turns ON an SCR, it stays ON until one of two things happen - either the circuit that the SCR is controlling stops drawing sufficient current to keep the SCR conducting, or a different signal is sent to the SCR to turn it off. On the other hand, a relay will stay $\mathrm{ON}$ only as long as the signal telling it to turn $\mathrm{ON}$ is present.

\section{2) Triacs:}


A Triac is essentially a bi-directional SCR; however, a Triac used in an AC circuit will reach one of the turn-off conditions "automatically", since the circuit is AC. The circuit the Triac controls will stop drawing current when the AC sine wave reaches 0 volts.

Some advantages of thyristors are:

1) There are no moving parts to wear out.

2) They are smaller than relays for smaller load currents.

3) Lower signal switching currents and voltages are required compared to relays.

Some disadvantages of thyristors are:

1) A minimum load current must be present for proper switching operation.

2) Heat must be properly dissipated from the device housing.

3) The proper circuit design depends significantly upon the type of load being switched.

4) Special care must be used when switching inductive loads.

5) A small leakage current/voltage may be present even when the device is off.

6) A common failure mode for Triacs is to fail $\mathrm{ON}$ when subjected to excessive current.

Highly inductive loads release a voltage spike when turned OFF that can cause a Triac to retrigger and switch back ON unintentionally. To prevent this, a "snubber" circuit or a special class of "snubber-less" Triacs is used. Examples of these are marketed under the trade names Alternistor (Teccor/Littelfuse), Snubberless (ST Microelectronics) and Hi-Com (NXP). This improvement is achieved at the expense of the ability to trigger the device in the 4th quadrant (negative voltage and positive gate current); however, this is usually no problem because this trigger mode is seldom used since even normal Triacs are least sensitive there.

\subsection{Residential Appliance Load Analysis}

Table 17 below summarizes the additional research we accomplished, compiling a list of residential electrical appliances and categorizing them by rated voltage, maximum rated operating current, power plug type, and suitable load control method. This helps us understand which various load control product configurations can be marketed towards which type of appliances.

\begin{tabular}{|l|c|c|c|c|c|c|}
\hline & \multicolumn{1}{c}{} & \multicolumn{2}{c}{ Load Control } \\
& $\begin{array}{c}\text { Wattage } \\
\text { Range } \\
\text { (Running) }\end{array}$ & $\begin{array}{c}\text { Rated } \\
\text { AC }\end{array}$ & $\begin{array}{c}\text { Max } \\
\text { Volts }\end{array}$ & $\begin{array}{c}\text { AC } \\
\text { Amps }\end{array}$ & Plug Type & \multicolumn{2}{c|}{ Relays } & Triacs \\
\hline $\begin{array}{l}\text { Air Cleaner } \\
\text { (Electronic) }\end{array}$ & $40-50$ & 120 & 0.42 & $120 / 15 \mathrm{~A}$ & OK & OK \\
\hline
\end{tabular}




\begin{tabular}{|c|c|c|c|c|c|c|}
\hline $\begin{array}{l}\text { Air Conditioner } \\
\text { (Central) }\end{array}$ & $1500-9200$ & $120 / 240$ & 38.33 & $\begin{array}{l}\text { 120/15A or } \\
120 / 20 \mathrm{~A} \text { or } \\
240 / 30 \mathrm{~A} \text { or } \\
240 / 50 \mathrm{~A} \text { or } \\
\text { Direct wired }\end{array}$ & $\mathrm{OK}$ & maybe \\
\hline $\begin{array}{l}\text { Air Conditioner } \\
\text { (Room) }\end{array}$ & $500-1855$ & $120 / 240$ & 15.46 & $\begin{array}{c}120 / 15 \mathrm{~A} \text { or } \\
120 / 20 \mathrm{~A} \text { or } \\
240 / 30 \mathrm{~A}\end{array}$ & $\mathrm{OK}$ & special \\
\hline Aquarium & $115-1200$ & 120 & 10.00 & $120 / 15 \mathrm{~A}$ & $\mathrm{OK}$ & $\mathrm{OK}$ \\
\hline Blanket, Electric & $60-400$ & 120 & 3.33 & $120 / 15 \mathrm{~A}$ & $\mathrm{OK}$ & $\mathrm{OK}$ \\
\hline Blender & $300-800$ & 120 & 6.67 & $120 / 15 \mathrm{~A}$ & $\mathrm{OK}$ & OK \\
\hline Can Opener & $100-180$ & 120 & 1.50 & $120 / 15 \mathrm{~A}$ & $\mathrm{OK}$ & $\mathrm{OK}$ \\
\hline Carving Knife & $90-95$ & 120 & 0.79 & $120 / 15 \mathrm{~A}$ & $\mathrm{OK}$ & $\mathrm{OK}$ \\
\hline $\begin{array}{l}\text { Cassette Tape } \\
\text { Recorder }\end{array}$ & $5-100$ & 120 & 0.83 & $120 / 15 \mathrm{~A}$ & $\mathrm{OK}$ & $\mathrm{OK}$ \\
\hline CD player & $35-85$ & 120 & 0.71 & $120 / 15 \mathrm{~A}$ & $\mathrm{OK}$ & $\mathrm{OK}$ \\
\hline Christmas Lights & $80-800$ & 120 & 6.67 & $120 / 15 \mathrm{~A}$ & $\mathrm{OK}$ & $\mathrm{OK}$ \\
\hline Clock/Radio & $5-200$ & 120 & 1.67 & $120 / 15 \mathrm{~A}$ & $\mathrm{OK}$ & $\mathrm{OK}$ \\
\hline Clothes Dryer, Gas & $300-700$ & 120 & 5.83 & $120 / 15 \mathrm{~A}$ & $\mathrm{OK}$ & special \\
\hline $\begin{array}{l}\text { Clothes Dryer, } \\
\text { Electric }\end{array}$ & $4000-5750$ & 240 & 23.96 & $240 \mathrm{~V} / 30 \mathrm{~A}$ & $\mathrm{OK}$ & special \\
\hline Clothes Washer & $500-1150$ & 120 & 9.58 & $120 / 15 \mathrm{~A}$ & $\mathrm{OK}$ & $\mathrm{OK}$ \\
\hline Coffee Pot & $200-360$ & 120 & 3.00 & $120 / 15 \mathrm{~A}$ & $\mathrm{OK}$ & $\mathrm{OK}$ \\
\hline Coffee Maker & $800-1750$ & 120 & 14.58 & $120 / 15 \mathrm{~A}$ & $\mathrm{OK}$ & $\mathrm{OK}$ \\
\hline $\begin{array}{l}\text { Curling/Straightening } \\
\text { Iron }\end{array}$ & $40-200$ & 120 & 1.67 & $120 / 15 \mathrm{~A}$ & $\mathrm{OK}$ & $\mathrm{OK}$ \\
\hline Dehumidifier & $350-785$ & 120 & 6.54 & $120 / 15 \mathrm{~A}$ & $\mathrm{OK}$ & $\mathrm{OK}$ \\
\hline Deep Fryer & 1000 & 120 & 8.33 & $120 / 15 \mathrm{~A}$ & $\mathrm{OK}$ & $\mathrm{OK}$ \\
\hline Dishwasher & $1200-2400$ & 120 & 20.00 & Direct wired & $\mathrm{OK}$ & $\mathrm{OK}$ \\
\hline Drill & 300 & 120 & 2.50 & $120 / 15 \mathrm{~A}$ & $\mathrm{OK}$ & $\mathrm{OK}$ \\
\hline Evaporative Cooler & 400 & 120 & 3.33 & $120 / 15 \mathrm{~A}$ & $\mathrm{OK}$ & $\mathrm{OK}$ \\
\hline \multicolumn{7}{|l|}{ Fans } \\
\hline 20-24" Window & 200 & 120 & 1.67 & $120 / 15 \mathrm{~A}$ & $\mathrm{OK}$ & $\mathrm{OK}$ \\
\hline Attic & $350-370$ & 120 & 3.08 & Direct wired & $\mathrm{OK}$ & $\mathrm{OK}$ \\
\hline Oscillating/Box & $30-175$ & 120 & 1.46 & $120 / 15 \mathrm{~A}$ & $\mathrm{OK}$ & $\mathrm{OK}$ \\
\hline Ceiling & $60-100$ & 120 & 0.83 & Direct wired & $\mathrm{OK}$ & $\mathrm{OK}$ \\
\hline Floor Polisher & 300 & 120 & 2.50 & $120 / 15 \mathrm{~A}$ & $\mathrm{OK}$ & $\mathrm{OK}$ \\
\hline Fondue Pot & 800 & 120 & 6.67 & $120 / 15 \mathrm{~A}$ & $\mathrm{OK}$ & $\mathrm{OK}$ \\
\hline Food Processor & $300-800$ & 120 & 6.67 & $120 / 15 \mathrm{~A}$ & $\mathrm{OK}$ & special \\
\hline Freezer (Upright) & $335-700$ & 120 & 5.83 & $120 / 15 \mathrm{~A}$ & $\mathrm{OK}$ & special \\
\hline
\end{tabular}




\begin{tabular}{|c|c|c|c|c|c|c|}
\hline Frying Pan/Skillet & $1150-1300$ & 120 & 10.83 & $120 / 15 \mathrm{~A}$ & $\mathrm{OK}$ & $\mathrm{OK}$ \\
\hline Furnace, Electric & $\begin{array}{l}7950- \\
26500\end{array}$ & 240 & 110.42 & Direct wired & $\mathrm{OK}$ & - no - \\
\hline Furnace Blower & $300-1000$ & 120 & 8.33 & Direct wired & $\mathrm{OK}$ & $\mathrm{OK}$ \\
\hline Garbage Disposal & $445-750$ & 120 & 6.25 & Direct wired & $\mathrm{OK}$ & $\mathrm{OK}$ \\
\hline Garage Door Opener & $350-725$ & 120 & 6.04 & $120 / 15 \mathrm{~A}$ & $\mathrm{OK}$ & OK \\
\hline $\begin{array}{l}\text { Grill, Outdoor } \\
\text { Electric }\end{array}$ & 1800 & 120 & 15.00 & $120 / 15 \mathrm{~A}$ & $\mathrm{OK}$ & $\mathrm{OK}$ \\
\hline Hair Dryer & $700-1875$ & 125 & 15.00 & $120 / 15 \mathrm{~A}$ & $\mathrm{OK}$ & $\mathrm{OK}$ \\
\hline Heating Pad & $50-65$ & 120 & 0.54 & $120 / 15 \mathrm{~A}$ & $\mathrm{OK}$ & $\mathrm{OK}$ \\
\hline Heater, Engine Block & $150-1000$ & 120 & 8.33 & $120 / 15 \mathrm{~A}$ & $\mathrm{OK}$ & $\mathrm{OK}$ \\
\hline Heater, Portable & $600-1500$ & 120 & 12.50 & $120 / 15 \mathrm{~A}$ & $\mathrm{OK}$ & $\mathrm{OK}$ \\
\hline Heat Lamp & 250 & 120 & 2.08 & $120 / 15 \mathrm{~A}$ & $\mathrm{OK}$ & $\mathrm{OK}$ \\
\hline Hedge Trimmer & 450 & 120 & 3.75 & $120 / 15 \mathrm{~A}$ & $\mathrm{OK}$ & $\mathrm{OK}$ \\
\hline $\begin{array}{l}\text { Home Security } \\
\text { System }\end{array}$ & 30 & 120 & 0.25 & $120 / 15 \mathrm{~A}$ & $\mathrm{OK}$ & $\mathrm{OK}$ \\
\hline Hot Plate & $1100-1320$ & 120 & 11.00 & $120 / 15 \mathrm{~A}$ & $\mathrm{OK}$ & $\mathrm{OK}$ \\
\hline Humidifier & $75-100$ & 120 & 0.83 & $120 / 15 \mathrm{~A}$ & $\mathrm{OK}$ & $\mathrm{OK}$ \\
\hline Iron & $1000-1200$ & 120 & 10.00 & $120 / 15 \mathrm{~A}$ & $\mathrm{OK}$ & $\mathrm{OK}$ \\
\hline Kettle & 1500 & 120 & 12.50 & $120 / 15 \mathrm{~A}$ & $\mathrm{OK}$ & $\mathrm{OK}$ \\
\hline Kiln & 5760 & 240 & 24.00 & $240 / 30 \mathrm{~A}$ & $\mathrm{OK}$ & $\mathrm{OK}$ \\
\hline \multicolumn{7}{|l|}{ Lighting } \\
\hline $\begin{array}{c}\text { Table Lamp } \\
\text { (Incandescent) }\end{array}$ & $60-180$ & 120 & 1.50 & $120 / 15 \mathrm{~A}$ & $\mathrm{OK}$ & $\mathrm{OK}$ \\
\hline $\begin{array}{l}\text { Fluorescent (2 tube } \\
4 \text { ft.) }\end{array}$ & 100 & 120 & 0.83 & $120 / 15 \mathrm{~A}$ & $\mathrm{OK}$ & special \\
\hline Microwave Oven & $625-1500$ & 120 & 12.50 & $120 / 15 \mathrm{~A}$ & $\mathrm{OK}$ & special \\
\hline Mixer & $100-225$ & 120 & 1.88 & $120 / 15 \mathrm{~A}$ & $\mathrm{OK}$ & special \\
\hline Mower, Electric & 1500 & 120 & 12.50 & $120 / 15 \mathrm{~A}$ & $\mathrm{OK}$ & $\mathrm{OK}$ \\
\hline Oil Furnace (Burner) & 260 & 120 & 2.17 & $120 / 15 \mathrm{~A}$ & $\mathrm{OK}$ & $\mathrm{OK}$ \\
\hline Oral Irrigator & $40-100$ & 120 & 0.83 & $120 / 15 \mathrm{~A}$ & $\mathrm{OK}$ & $\mathrm{OK}$ \\
\hline Popcorn Popper & $250-1400$ & 120 & 11.67 & $120 / 15 \mathrm{~A}$ & $\mathrm{OK}$ & $\mathrm{OK}$ \\
\hline Personal Computer & $20-500$ & 120 & 4.17 & $120 / 15 \mathrm{~A}$ & $\mathrm{OK}$ & $\mathrm{OK}$ \\
\hline Power Drill & $250-1000$ & 120 & 8.33 & $120 / 15 \mathrm{~A}$ & $\mathrm{OK}$ & special \\
\hline Printer/Photocopier & $20-1500$ & 120 & 12.50 & $120 / 15 \mathrm{~A}$ & $\mathrm{OK}$ & $\mathrm{OK}$ \\
\hline Projector & $500-850$ & 120 & 7.08 & $120 / 15 \mathrm{~A}$ & $\mathrm{OK}$ & $\mathrm{OK}$ \\
\hline Roaster & 1335 & 120 & 11.13 & $120 / 15 \mathrm{~A}$ & $\mathrm{OK}$ & $\mathrm{OK}$ \\
\hline Range & $\begin{array}{c}12200- \\
12500\end{array}$ & 240 & 52.08 & $240 / 50 \mathrm{~A}$ & $\mathrm{OK}$ & - no - \\
\hline Record Player & $30-100$ & 120 & 0.83 & $120 / 15 \mathrm{~A}$ & $\mathrm{OK}$ & $\mathrm{OK}$ \\
\hline
\end{tabular}




\begin{tabular}{|c|c|c|c|c|c|c|}
\hline Refrigerator-Freezer & $380-800$ & 120 & 6.67 & $120 / 15 \mathrm{~A}$ & $\mathrm{OK}$ & $\mathrm{OK}$ \\
\hline Sander & $1000-1200$ & 120 & 10.00 & $120 / 15 \mathrm{~A}$ & $\mathrm{OK}$ & $\mathrm{OK}$ \\
\hline Satellite Dish & $15-40$ & 120 & 0.33 & $120 / 15 \mathrm{~A}$ & $\mathrm{OK}$ & $\mathrm{OK}$ \\
\hline Saw (Circular) & $900-1400$ & 120 & 11.67 & $120 / 15 \mathrm{~A}$ & $\mathrm{OK}$ & $\mathrm{OK}$ \\
\hline Sewing Machine & $75-100$ & 120 & 0.83 & $120 / 15 \mathrm{~A}$ & $\mathrm{OK}$ & $\mathrm{OK}$ \\
\hline Shaver & 15 & 120 & 0.13 & $120 / 15 \mathrm{~A}$ & $\mathrm{OK}$ & $\mathrm{OK}$ \\
\hline Slow Cooker & $150-400$ & 120 & 3.33 & $120 / 15 \mathrm{~A}$ & $\mathrm{OK}$ & $\mathrm{OK}$ \\
\hline Stereo & $10-110$ & 120 & 0.92 & $120 / 15 \mathrm{~A}$ & $\mathrm{OK}$ & $\mathrm{OK}$ \\
\hline Spa & $\begin{array}{l}1300- \\
11000\end{array}$ & $120 / 240$ & 45.83 & $\begin{array}{c}120 / 15 \mathrm{~A} \text { or } \\
240 / 50 \mathrm{~A}\end{array}$ & $\mathrm{OK}$ & - no - \\
\hline Sump Pump & $60-1050$ & 120 & 8.75 & $120 / 15 \mathrm{~A}$ & $\mathrm{OK}$ & $\mathrm{OK}$ \\
\hline Sun Lamp & 280 & 120 & 2.33 & $120 / 15 \mathrm{~A}$ & $\mathrm{OK}$ & $\mathrm{OK}$ \\
\hline $\begin{array}{l}\text { Swimming Pool } \\
\text { Heater }\end{array}$ & $\begin{array}{l}5000- \\
18000\end{array}$ & 240 & 75.00 & Direct wired & $\mathrm{OK}$ & maybe \\
\hline $\begin{array}{l}\text { Swimming Pool } \\
\text { Pump }\end{array}$ & $500-2000$ & $120 / 240$ & 15.00 & $\begin{array}{c}\text { 120/15A or } \\
240 / 30 \mathrm{~A}\end{array}$ & $\mathrm{OK}$ & $\mathrm{OK}$ \\
\hline Telephone (Cordless) & $40-150$ & 120 & 1.25 & $120 / 15 \mathrm{~A}$ & $\mathrm{OK}$ & $\mathrm{OK}$ \\
\hline Television & $70-350$ & 120 & 2.92 & $120 / 15 \mathrm{~A}$ & $\mathrm{OK}$ & $\mathrm{OK}$ \\
\hline Toaster & $800-1650$ & 120 & 13.75 & $120 / 15 \mathrm{~A}$ & $\mathrm{OK}$ & $\mathrm{OK}$ \\
\hline Toaster Oven & $1350-1550$ & 120 & 12.92 & $120 / 15 \mathrm{~A}$ & $\mathrm{OK}$ & $\mathrm{OK}$ \\
\hline Toothbrush, Electric & $1.1-10$ & 120 & 0.08 & $120 / 15 \mathrm{~A}$ & $\mathrm{OK}$ & - no - \\
\hline Trash Compactor & 400 & 120 & 3.33 & $120 / 15 \mathrm{~A}$ & $\mathrm{OK}$ & $\mathrm{OK}$ \\
\hline Typewriter & $50-200$ & 120 & 1.67 & $120 / 15 \mathrm{~A}$ & $\mathrm{OK}$ & $\mathrm{OK}$ \\
\hline Vacuum (Central) & $1000-1600$ & $120 / 240$ & 13.33 & Direct wired & $\mathrm{OK}$ & special \\
\hline Vacuum (Portable) & $100-1100$ & 120 & 9.17 & $120 / 15 \mathrm{~A}$ & $\mathrm{OK}$ & special \\
\hline VCR & $15-175$ & 120 & 1.46 & $120 / 15 \mathrm{~A}$ & $\mathrm{OK}$ & $\mathrm{OK}$ \\
\hline Waffle Maker & 1200 & 120 & 10.00 & $120 / 15 \mathrm{~A}$ & $\mathrm{OK}$ & $\mathrm{OK}$ \\
\hline Water Bed Heater & $250-450$ & 120 & 3.75 & $120 / 15 \mathrm{~A}$ & $\mathrm{OK}$ & $\mathrm{OK}$ \\
\hline Water Heater & $2475-4475$ & 240 & 18.65 & $240 / 30 \mathrm{~A}$ & $\mathrm{OK}$ & $\mathrm{OK}$ \\
\hline Water Softener & 5 & 120 & 0.04 & $120 / 15 \mathrm{~A}$ & $\mathrm{OK}$ & - no - \\
\hline Weed Trimmer & 500 & 120 & 4.17 & $120 / 15 \mathrm{~A}$ & $\mathrm{OK}$ & $\mathrm{OK}$ \\
\hline Well Pump & $300-2250$ & $120 / 240$ & 18.75 & Direct wired & $\mathrm{OK}$ & special \\
\hline
\end{tabular}

\section{Table 17 - Household Appliances - Power Rating/Configuration}

\subsection{Conclusions}

Both $120 \mathrm{~V}$ and $120 \mathrm{~V} / 240 \mathrm{~V}$ appliances can be controlled via either relays or Triacs. 
Relays can be used to control virtually any load type. A relay was used in the Scientific Atlanta DCU-S2000 load control utility box we investigated, which was used by our local utility for oneway summertime load control programs it has offered for several years.

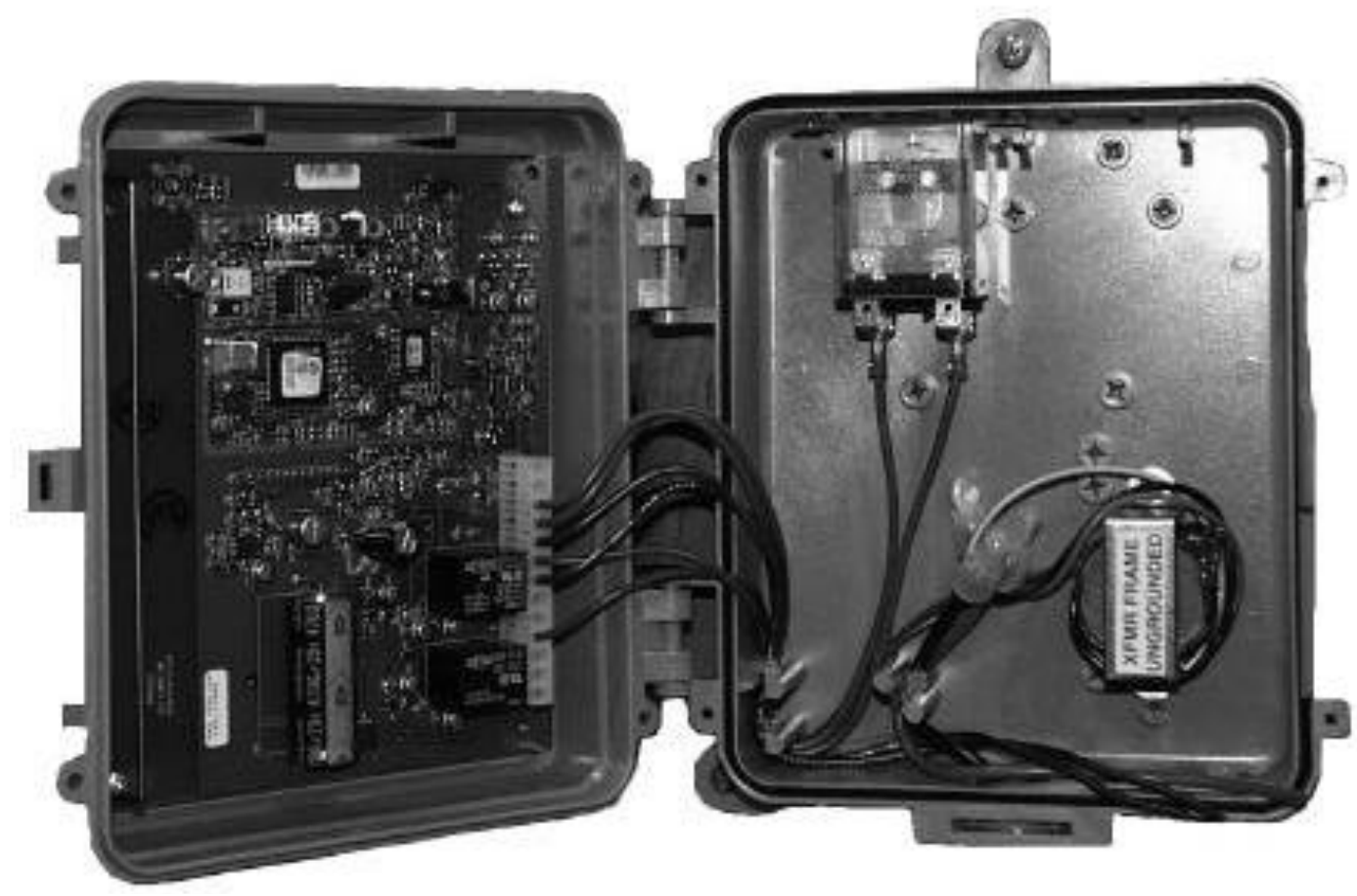

Figure 18: Utility Load Control Module - Scientific Atlanta DCU-S2000

According to the Electric Technology Center

(http://www.electrictechnologycenter.com/pdf/ccet_dr_pilot_final_report_20090624.pdf):

"Residential Direct Load Control (DLC) is a proven concept. Load switches, thermostats, and the associated remote enabling technology (radio communications, etc.) have been in use for some time, even since the 1970's. However, most previous efforts to implement DLC relied on one-way communication from a central dispatch via radio to the load controlling devices (switches, thermostats), and typically used radio communications."

One of the chief drawbacks of these existing one-way systems is that the utility broadcasting the load control signal has no idea which receivers heard the broadcast, interpreted it correctly, and shut off a running load to save energy as a result. Without the two-way communication systems targeted by research such as this, there will be no way for the utility to advance to a conservation program which actually rewards customers for responsive appliance load behaviors proportional to their savings contribution. 
Thyristors (Triacs) must be designed around a particular class of load types (ie: resistive heaters, incandescent lights, inductive motors, etc.), and the load current must exceed a minimum threshold (e.g., 0.1 Amps) for successful control.

Microcontroller chipsets like the Freescale MC13213 and the Texas Instruments CC2530 chipsets are easily capable of controlling both relays and Triacs with some custom interface circuits, and the Springboard Engineering team has substantial experience designing as well as qualifying (through reliability tests and failure-rate analyses) load-switching control systems for a wide variety of appliance loads.

In Phase 2, we recommend testing and qualifying a number of candidate relays with a variety of heavy load types based on the product class of appliances for which Springboard Engineering targets prototyping and then commercializing load control solutions.

We have determined that the chipsets have outputs (see Table 18 below) sufficient for interfacing with circuitry to drive relays that can switch 30-Amp loads, and have met the objectives for Phase 1.

\begin{tabular}{|c|c|c|}
\hline Feature & TI CC2530 & Freescale MC13213 \\
\hline ROM & $32 \mathrm{~K} / 64 \mathrm{~K} / 128 \mathrm{~K} / 256 \mathrm{~K}$ Flash & 16K/32K/60K Flash \\
\hline $\boldsymbol{R A M}$ & $8 \mathrm{~K}$ & $1 \mathrm{~K} / 2 \mathrm{~K} / 4 \mathrm{~K}$ (respectively) \\
\hline RF chip & 2.4Ghz, 802.15.4 transceiver & 2.4Ghz, 802.15.4 transceiver \\
\hline Package & 6mm X 6mm QFN,40-pin & 9mm X 9mm LGA,71-pin \\
\hline$A D C$ & 12-bit, 8 channels & 10-bit, 8 channels \\
\hline \multirow[t]{2}{*}{$I / O$} & $19 \mathrm{GPIO}, 4 \mathrm{ma}$ & 24 GPIO, $2 \mathrm{ma}$ \\
\hline & $2 \mathrm{GPIO}, 20 \mathrm{ma}$ & $8 \mathrm{GPIO}, 10 \mathrm{ma}$ \\
\hline uC chip core & Hi-perf, Low-power 8051 & Hi-perf, Low-power HCS08 \\
\hline Voltage & $2-3.6 \mathrm{~V}$ & $2.08-3.6 \mathrm{~V}$ \\
\hline \multirow[t]{2}{*}{$\begin{array}{l}\text { Active mode } \\
\text { current (at } 3 \mathrm{~V} \text { ) }\end{array}$} & $3.4 \mathrm{ma}$ at $16 \mathrm{Mhz}, \mathrm{CPU}$ but no RF & $6.6 \mathrm{ma}$ at $16 \mathrm{Mhz}, \mathrm{CPU}$ but no $\mathrm{RF}$ \\
\hline & $6.5 \mathrm{ma}$ at $32 \mathrm{Mhz}, \mathrm{CPU}$ but no RF & \\
\hline \multirow[t]{2}{*}{$\begin{array}{l}\text { Modem current (at } \\
2.7 \mathrm{~V})\end{array}$} & $\begin{array}{l}24.3 \mathrm{ma} \text { at } 32 \mathrm{Mhz}, \text { no CPU, max } \\
\mathrm{RX}\end{array}$ & $37 \mathrm{ma}$ at $16 \mathrm{Mhz}$, no CPU, $\max \mathrm{RX}$ \\
\hline & $\begin{array}{l}33.5 \mathrm{ma} \text { at } 32 \mathrm{Mhz} \text {, no CPU max } \\
\text { TX }\end{array}$ & \\
\hline \multirow[t]{3}{*}{$\begin{array}{l}\text { Low power mode } \\
\text { current (at } 3 \mathrm{~V} \text { ) }\end{array}$} & $.2 \mathrm{ma}$ at $32.768 \mathrm{Khz}$, Quick wakeup & $.56 \mathrm{ma}$ at $2 \mathrm{Mhz}$, Quick wakeup \\
\hline & 1 ua at $32.768 \mathrm{Khz}$, Sleep timer & .98 ua at $1 \mathrm{Khz}, \mathrm{RTI}$ wakeup \\
\hline & .4 ua, External interrupt & .56 ua, External interrupt \\
\hline
\end{tabular}




\begin{tabular}{|l|l|l|} 
Serial Ports & 2 SPI/UART, full duplex & 2 SCI, full duplex \\
\hline Security & Coprocessor plus integrated chipset & Integrated chipset \\
\hline \multirow{2}{*}{ Sense inputs } & One 8-bit, two 16-bit & One 4-channel, one 1-channel \\
\cline { 2 - 3 } & Battery & \\
\cline { 2 - 3 } & Temperature & \\
\hline
\end{tabular}

Table 18 - Wireless Microcontroller Chipsets Compared 


\section{Task 6 - User Interface, Standby Power and Future Expectations}

\subsection{Phase 1 Plan}

Our Task 6 goals and expectations were, as stated in our Phase 1 proposal's project narrative:

"In the end, while some future smart-grid compatible process-type appliances will be able to reduce their operating power for certain periods of time while remaining active with little customer inconvenience (such as the smart clothes dryer which continues to run with its heater briefly de-energized in response to a critical power event), the not-grid-ready process-type appliances will serve best by being provided the means to indicate to the end user whether the current time is a 'green' (low-cost), 'yellow' (mid-cost or shortly becoming high-cost), or 'red' (high-cost) electricity-use time period, while still allowing that user to decide whether that appliance should be operated at that time. "

"What would be desirable by both the utility and the consumer would be an alternative solution for non-smart-grid-compatible appliances, having the following characteristics:

- Consumer-initiated and governed (limited utility or government coaxing needed to market or sell the energy cost-saving device)

- Installable by either a novice or do-it-yourselfer (eliminating professional installer/access requirement)

- $\quad$ Costing an order of magnitude less than the current utility-driven solutions (providing a breakthrough-level implementation-savings advantage)

- Consuming not more than a small fraction of the energy to operate as compared to the expected peak energy savings (minimal energy use 'overhead')

- Useful with a broad scope of household appliance types (maximizing the collective peakenergy savings benefit opportunities)"

"Our expectation is that as a result of this research we will succeed in identifying and proving the feasibility of at least one low-cost chipset that will be capable of all of the following:

- Operating from any in-house power line or outlet using very little power

- Communicating two-way with AMI signals from various near or far sources

- Receiving accurate current time and day information (for time-of-day usage shifting) from a standard source using wireless one-way communications

- Understanding and processing time-of-day rate and period information and peak-demand signals

- Controlling outputs to a separate (or integrated, say, as in a new smart outlet product) loadcontrol module (especially for 'persistent-use' appliance types)

- Controlling indicators to provide feedback to the end user regarding the energy cost time period currently active (especially for 'process-oriented' appliance types)"

"We expect this chipset to be adaptable to control a number of different commercially marketable smart-controller-based devices for non-smart appliances. Further research and 
development of these smart controllers along with a Commercialization Plan is expected to become part of the Phase II effort."

\subsection{Overview}

The consumer is going to experience increasing pressure to modify their energy usage. This pressure will flow down from federal and/or state incentivized mandates on electrical utilities and electricity distributor/management companies to create retail programs for residential customers that reduce peak demand usage by a certain percentage. These electricity providers will in turn provide options to consumers that include both economic incentives and penalties for peak load reductions, motivating these various electricity users to avoid additional cost increases by:

- a small amount - by signing up for a utility-managed demand response summer loadshedding program for central air conditioners and/or electric water heaters,

- a medium amount - by changing their family usage habits to conserve or shift consumption by their appliances, or

- a large amount - by investing in new smart products which help them easily understand their energy usage at the appliance level and help automate the peak-avoidance, loadshifting process for them.

There are a number of different programs that different utilities will likely be using to implement peak-limiting, energy-leveling strategies for residences. One of the greatest challenges will be the increasing difficulty in accurately projecting future demand once a) energy prices are progressively deregulated in favor of the energy distributors' commitments to implement peakreducing programs of some sort, and b) energy brokers increase implementation of various types of energy-shifting schemes, avoiding (and creating) new peak time periods much more dynamic that any current models show.

With some of these programs, the only way for residential customers to successfully adapt their variable energy use to these increasingly unpredictable low-cost time periods will be to have load control married to their energy-using appliances and responsive to the energy provider's demand response communications through the home information gateway (smart meter or internet hot spot).

\subsection{Research Summary}

The current residential load monitor/control solutions available on the market today are not based on the winning in-home communications standard for the Smart Grid, Zigbee Smart Energy 2.0, so newer solutions will need to be. Current demand response pilot projects are forerunners, but do not have the devices needed by the bill-paying residential customers outlined above; especially not those needed by customers with limited means to purchase the coming "smart" appliances and whole-house management systems. 
At least one type of device that we wish to enable through our research and development is a load control device which:

1) Hears the pricing and curtailment messages broadcast from the electric utility provider,

2) Is capable of automatically responding by disabling power to a connected appliance,

3) Allows the customer the option of overriding the power disabling function manually,

4) Provides indication of its electricity use and load status,

5) Can be easily purchased and installed by the end-user, and

6) Costs significantly less that the electricity cost savings expected to be achieved by its use.

Table 18 above summarizes the features of the two main controller chipsets we evaluated during this project. It seems clear that both are excellent choices for basic wireless applications and both consume very little standby power in their power saving modes. In discussions with the manufacturers of these chips, however, it seems clear that the direction of the Smart Energy standard is going to require additional memory. This makes it likely that some Smart Grid devices in the home will need to be based on wireless chipsets with larger memory footprints or those that can address external memory. Concerns for the handling of security keys and such will likely be another issue that shakes out of the ongoing standards development and determines the partitioning of functions among chipsets in a given end product.

\subsection{Conclusions}

As we finished Phase 1 and looked forward into Phase 2, we ideated and sketched some product concepts (See Figures 19 - 22 below) that we envision being possible based on the results of our continued research.
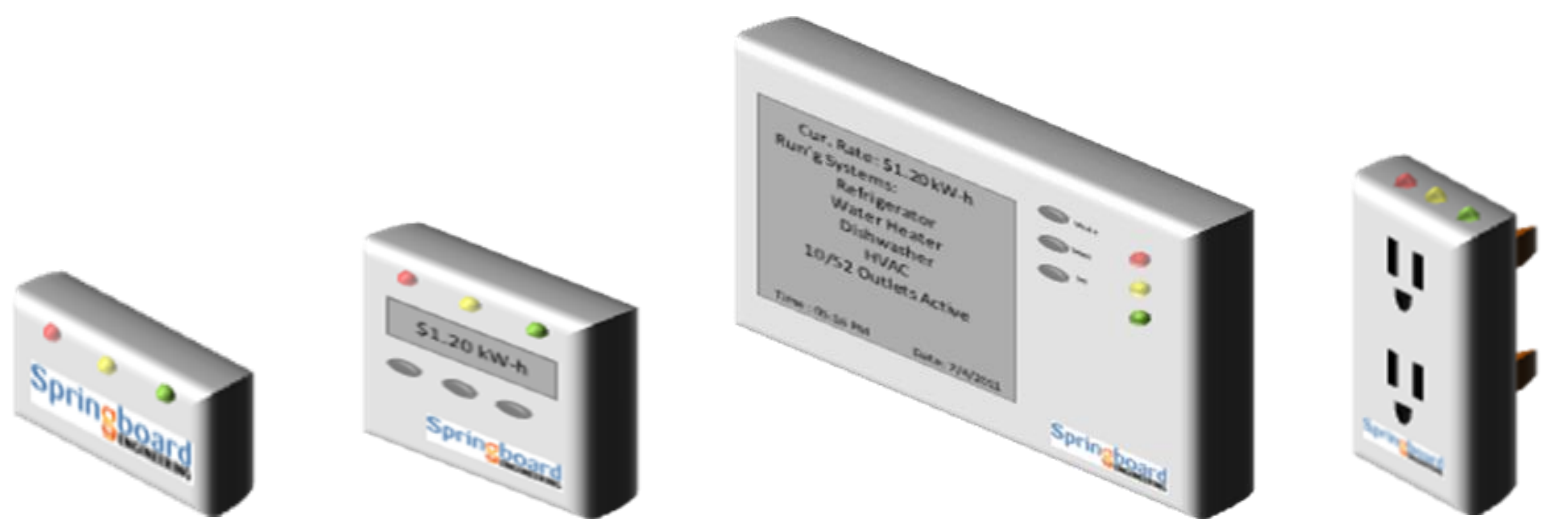

Figure 19: Concept Wireless Time-aware Devices that Communicate with the AMI and Indicate Cost Level to the Customer 


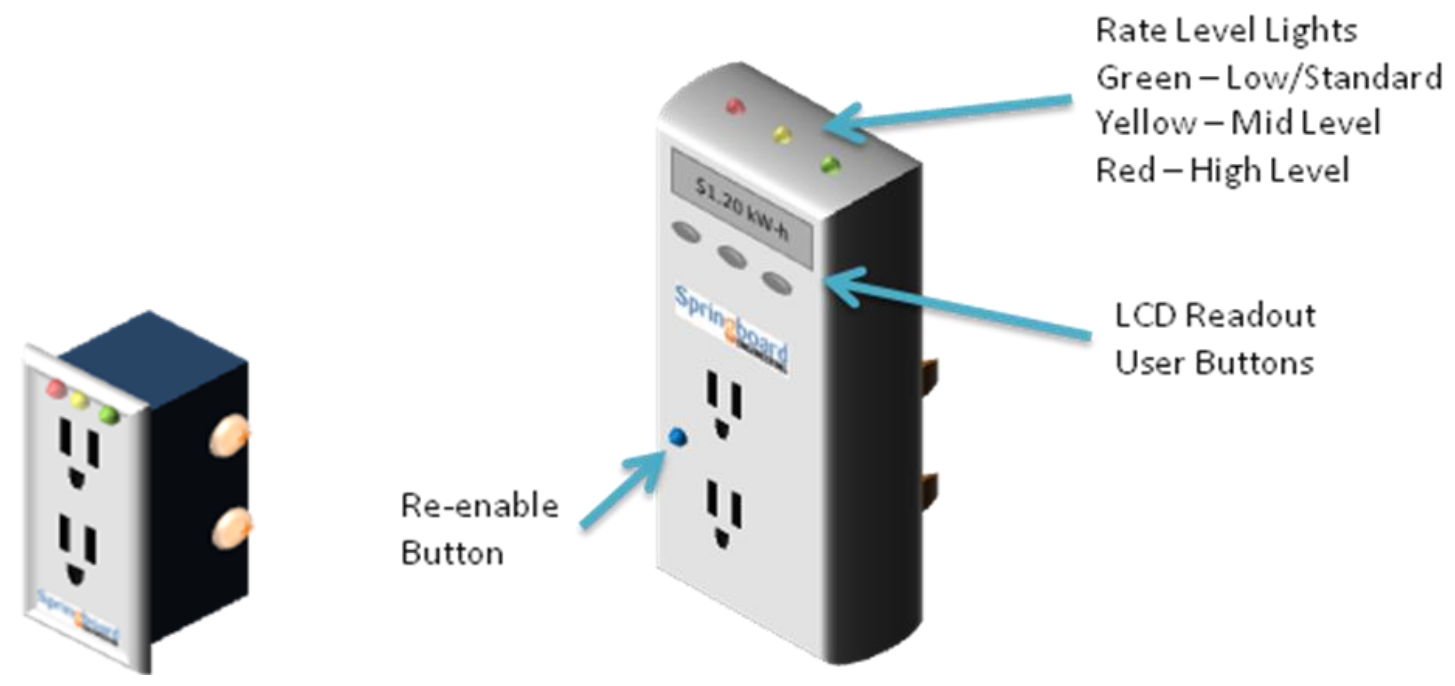

Figure 20: Concept Wireless Devices that Monitor Prices/Power and Disable Power to Plugged-in Loads

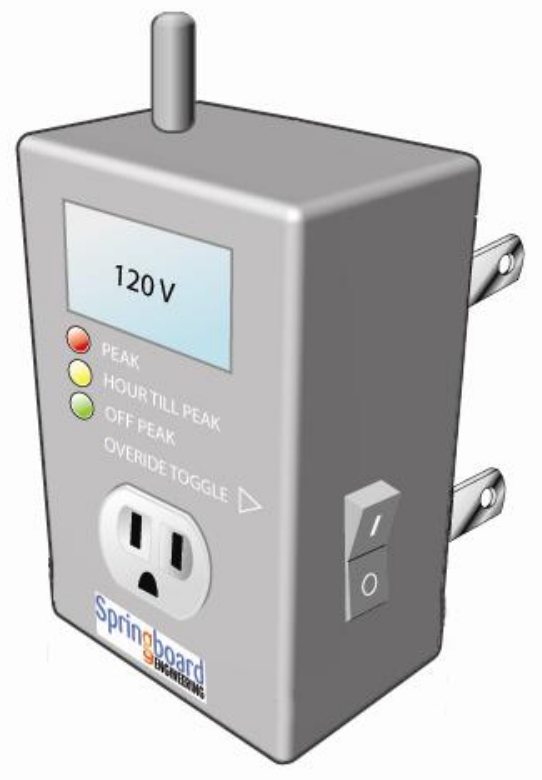

Figure 21: Concept Wireless Load Monitor and Control Device with Integral Customer Override Switch 


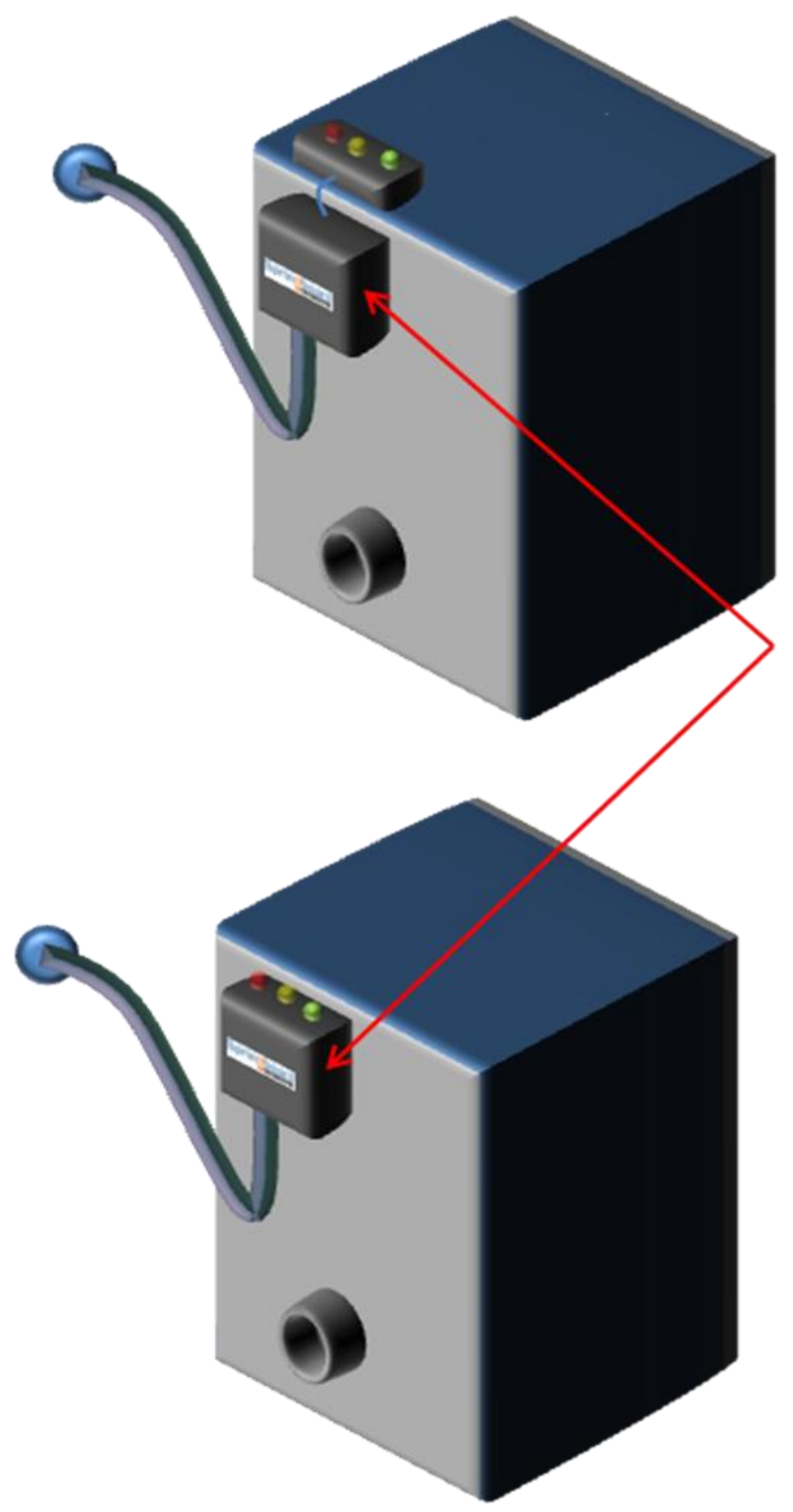

Standard Electric Dryer w/Monitoring and Control Module v. 2

Tethered Indictor Lights on top of unit.

Module replaces standard terminal cover.

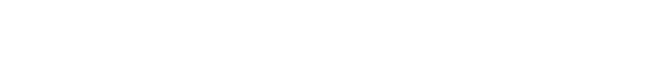

\section{Standard Electric Dryer \\ w/Monitoring and \\ Control Module v. 1}

Figure 22: Concept Terminal Block Options for Electric Dryer which Wirelessly Monitors and Controls Power to the Attached 240VAC Power Cord 